Research Article

\title{
The Impact of LED Colour Rendering on Reaction Time of Human Eyes in Tunnel Interior Zone
}

\author{
Li-Li Dong $(\mathbb{D}$, Qi Lou $(\mathbb{D}$, Peng Liu $(\mathbb{D}$, and Wen-Hai Xu $(\mathbb{C}$ \\ School of Information Science and Technology, Dalian Maritime University, Dalian 116026, China \\ Correspondence should be addressed to Li-Li Dong; donglili@dlmu.edu.cn
}

Received 7 May 2021; Accepted 14 August 2021; Published 28 August 2021

Academic Editor: Kun An

Copyright (c) $2021 \mathrm{Li}-\mathrm{Li}$ Dong et al. This is an open access article distributed under the Creative Commons Attribution License, which permits unrestricted use, distribution, and reproduction in any medium, provided the original work is properly cited.

\begin{abstract}
The long reaction time of human eyes will increase the probability of traffic accidents in tunnels which can be reduced by improving lighting conditions. In recent years, light-emitting diodes (LEDs) have replaced the traditional lighting source in a tunnel. Colour rendering index 2012 (CRI2012, a colour rendering evaluation index) is the most suitable evaluation method for colour rendering of LEDs. In order to study the impact of colour rendering of LEDs on the reaction time of human eyes, a driving simulation environment was designed. First, three CCTs (correlated colour temperatures), four CRI2012s, and eight colours of targets were assessed using mesopic photometry model MES-2. The calculation results indicated that the contrast of targets had a positive correlation with CRI2012 and had a negative correlation with CCT. Then, reaction time experiment was conducted in simulated tunnel environments. There are 30 observers who participated. The results show that the LEDs with higher CRI2012 and lower CCT in tunnel is conducive to reducing the reaction time of human eyes. High CRI2012 enables drivers to accurately and quickly identify colours. This paper provides a reference for the design of light source parameters, roads, walls, and warning signs in the tunnel.
\end{abstract}

\section{Introduction}

The chance of traffic accidents at the tunnel interior zone is less than open roads [1]; because of the special structure of the tunnel, the accidents will be more serious than the open road such as large number of casualties and property losses $[2,3]$. So, it is significant to analyse the causes of accidents, improve the traffic conditions, and reduce the probability of accidents in the tunnel interior zone.

Traffic accidents in the tunnel interior zone include rearend collision and collision wall [1]. The main reason for traffic accidents in the tunnel is that the driver has a longer reaction time to the vehicle or wall [4]. Reaction time is the time required from seeing the target unclearly to clearly [2]. The possibility of traffic accidents in the tunnel is positively correlated with the reaction time [5]; the longer reaction time will lead to further braking distance, so it is more likely to cause traffic accidents [6-8]. If the reaction time can be shortened, the safety of driving in a tunnel can be improved. Reaction time is mainly affected by tunnel lighting environment [2]. For a long time, CCT and colour rendering of lighting sources at tunnels are fixed by the limitation of lighting lamps. So, the setting of tunnel lighting is only based on the luminance in China $[9,10]$.

Recently, the LEDs are replacing the traditional light source in the tunnel [11-14] because characteristics of high luminous efficiency and long life of LEDs $[15,16]$. Consider the influence of the colour rendering and CCT of the LEDs on driving in the tunnel because the colour rendering and the CCT of the LED are not fixed.

Compared with colour rendering, CCT on tunnel driving safety-related research is relatively comprehensive [17-20]. In 2007 [21], Yamamoto et al. conducted experiments in a tunnel using high-frequency fluorescent lamps and lowpressure sodium lamps. The experimental results show that the use of light source of high colour rendering can more accurately show the colour of the equipment and the car ahead in the tunnel. In 2016 [22], Deng et al. used two light sources with different colour rendering properties to observe small targets in tunnels. They found that the better the colour rendering of tunnel light sources is, the stronger the driver's recognition ability of obstacles is, which is more conducive 
to driving safety and lighting energy saving. In 2017 [23], Zhang et al. used 15 lighting combinations with a different luminance and CCT in the tunnel. Experiments show that the appropriate combination of CCT and colour rendering of LED can improve the lighting efficiency of the light source in the tunnel and show better visual performance.

Although there are few studies on the application of colour rendering in tunnel lighting, more in indoor scenarios [24-28], the LEDs with high colour rendering are positive for indoor lighting. However, the results of these studies are basically based on the subjective feelings of the observer, and the impact of CCT on vision is not considered. Most of the experimental objectives are set to single colour; in real tunnels, the colour of targets cannot be single. The luminance in the tunnel is in mesopic vision luminance. In this luminance range, the human eye can perceive the colour of the object [29].

According to the aforementioned studies, the colour rendering has a significant impact on human eyes, but few studies have linked colour rendering to tunnel traffic safety. Therefore, this paper studies the impact of LED colour rendering on the safety of the tunnel interior zone and mainly the impact of different colour rendering of LEDs on reaction time of human eyes, considering the impact of different colours of target and CCTs on the reaction time. The research results will provide some suggestions for the formulation of tunnel lighting rules.

\section{The Evaluation Method for Colour Rendering of LED}

Colour rendering is generally expressed by CRI in the range of $0-100$, and the CRI of sunlight is 100 [30]. CRI has some problems in evaluating LEDs. So, two new evaluation methods appear, Colour Quality Scale (CQS) and CRI2012 (based on CRI) [31, 32]. Therefore, in order to study the impact of LED colour rendering on reaction time of human eyes, firstly, a most suitable evaluation index to evaluate the colour rendering of the LED needs to be selected.

In 2005, Yoshi and Wendy, scholars of the National Institute of Standards and Technology (NIST), presented a new objective evaluation method CQS. CQS uses the CAT02 chromatic adaptation formula to improve the accuracy of the chromatic adaptation formula and replaces the mean value with the root mean square error to improve the statistical rationality. Comparing with CRI, CQS is more exact in evaluating the colour rendering of LEDs. However, Nicola Pousset et al. [33] validated the colour preference degree of the CQS and found that the true colour quality of the LEDs differed greatly from the CQS value. CQS could not accurately represent the colour quality of the light source.

Based on the previous problems in colour rendering evaluation, CIE established TCI-90 technical committee, which proposed CRI2012. The improvement of the CRI2012 evaluation system includes use of CAM02-UCS colour space and CAT02 chromatic adaptation formula, use of new 17 colour samples $\mathrm{H} 17$ with uniform spectral distribution, which can help to correctly evaluate the colour rendering of spectral discontinuous light sources, and use of new calculation formulas to enhance the influence of extreme values of special colour rendering index on general colour rendering index. These improvements make CRI2012's evaluation of the colour rendering of LEDs more consistent with the results of visual experiments.

Therefore, CRI2012 will be more suitable for the evaluation of colour rendering of LED. Therefore, in this paper, CRI2012 is selected as the evaluation index of colour rendering.

\section{Impact of CRI2012 on Contrast of the Target}

Driving safety is closely related to reaction time of human eyes. The reaction time is directly affected by the contrast of the target. The higher the contrast, the shorter the reaction time [34-36]. In order to study the influence of CRI2012 on driving safety in the tunnel, it is necessary to study the effect of CRI2012 on the contrast of targets. In order to study the impact of CRI2012 on the contrast of targets, it is necessary to give the contrast calculation formula:

$$
C=\left|\frac{L_{t}-L_{b}}{L_{b}}\right|,
$$

where $\mathrm{C}$ is the contrast, $L_{t}$ is the luminance of the target, and $L_{b}$ is the luminance of the background. Contrast is only affected by target luminance and background luminance. Contrast represents the difference between the target luminance and the background luminance. The larger the difference is, the higher the contrast is and the better to reduce the reaction time of human eyes.

According to the research, the luminance measured by the instrument is not consistent with the actual perception luminance by the human eyes (perception luminance for short) at the mesopic vision luminance [20, 37]. So, the perceived luminance under the mesopic vision luminance needs to be calculated. The calculation method of the perceptual luminance to the targets and background $\left(L_{t}\right.$ and $\left.L_{b}\right)$ is shown in formulas (2) and (3):

$$
\begin{aligned}
L_{t} & =\int k_{m} V_{\text {mes }}(\lambda) L_{\mathrm{TSPD}}(\lambda) \mathrm{d} \lambda, \\
L_{b} & =\int k_{m} V_{\text {mes }}(\lambda) L_{\mathrm{BSPD}}(\lambda) \mathrm{d} \lambda,
\end{aligned}
$$

where $k_{m}$ refers to maximum spectral light performance corresponding to mesopic vision luminance, $V_{\text {mes }}(\lambda)$ is the mesopic spectral luminous efficiency function, and $L_{\mathrm{TSPD}}(\lambda)$ and $L_{\mathrm{BSPD}}(\lambda)$ refer to the spectral power distribution (SPD) of the target and the background measured by the spectral radiance meter.

3.1. $L_{\mathrm{TSPD}}(\lambda)$ and $L_{\mathrm{BSPD}}(\lambda) . L_{\mathrm{TSPD}}(\lambda)$ and $L_{\mathrm{BSPD}}(\lambda)$ refer to the SPDs of the target and the background measured by the spectral radiance meter. Before measuring $L_{\mathrm{TSPD}}(\lambda)$ and $L_{\mathrm{BSPD}}(\lambda)$, we need to set up the LED used in the experiment. Four CRI2012s and three CCTs are selected in this experiment, four CRI2012s are 55, 65, 75, and 85 and three CCTs are $2800 \mathrm{k}, 4500 \mathrm{k}$, and $6400 \mathrm{k}$, and there are 12 lighting conditions. The SPDs of LEDs are shown in Figure 1. Table 1 shows the comparison of theoretical and practical 
parameters of the LED. In order to not only meet the tunnel lighting rules but also make the experimental conclusion more universal, we set the ambient luminance of the experiment as $1 \mathrm{~cd} / \mathrm{m} 2$.

The SPD of 9 colours under 12 lighting conditions was tested, as shown in Figure 2. The background colour is similar to asphalt. All the SPDs measured by spectrophotometer Konica-Minolta CS-2000 and cs-s10w are shown in Figure 3.

3.2. $k V_{\text {mes }}(\lambda) . k V_{\text {mes }}(\lambda)$ refers to the mesopic spectral luminous efficiency function. The luminance of tunnel lighting is $1-10 \mathrm{~cd} / \mathrm{m} 2$. And, the luminance environment is $1 \mathrm{~cd} / \mathrm{m} 2$ in this experiment. This luminance is at the mesopic vision luminance, and we choose the MES-2 [38-42] model to calculate $V_{\text {mes }}(\lambda)$. The calculation of $V_{\text {mes }}(\lambda)$ formula is as follows; then, $k_{m}$ can be calculated by 5 . The whole $k_{m} V_{\text {mes }}(\lambda)$ calculation process is shown in Figure 4:

$$
L_{p}=\int 683 V(\lambda) L_{\mathrm{SPD}}(\lambda) \mathrm{d} \lambda
$$

$$
\begin{aligned}
k_{m} & =\frac{6831 \mathrm{~m} \cdot \mathrm{W}^{-1}}{V_{\text {mes }}\left(\lambda_{0}\right)}, \\
V_{\text {mes }}(\lambda) & =683 \frac{m_{2} V(\lambda)+\left(1-m_{2}\right) V^{\prime}(\lambda)}{m_{2}+\left(1-m_{2}\right) V^{\prime}\left(\lambda_{0}\right)}\left(0 \leq m_{2} \leq 1\right), \\
m_{2, n} & =0.3334 \log L_{\text {mes }, n}+0.767\left(0 \leq m_{2, n} \leq 1\right), \\
L_{\text {mes }, n} & =\frac{m_{2, n-1}+\left(1-m_{2, n-1}\right)(S / P) V^{\prime}\left(\lambda_{0}\right)}{m_{2, n-1}+\left(1-m_{2, n-1}\right) V^{\prime}\left(\lambda_{0}\right)} L_{p}, \\
\frac{S}{P} & =\frac{1700 \int_{380}^{730} V^{\prime}(\lambda) L_{\mathrm{SPD}}(\lambda) \mathrm{d} \lambda}{683 \int_{380}^{730} V(\lambda) L_{\mathrm{SPD}}(\lambda) \mathrm{d} \lambda} .
\end{aligned}
$$

$V_{\text {mes }}\left(\lambda_{0}=555 \mathrm{~nm}\right)$ is the value of $V_{\text {mes }}(\lambda)$ when $\lambda=555 \mathrm{~nm} . L_{p}$ refers to the luminance of targets and background in the photopic vision, whose units of measurement is $\mathrm{cd} / \mathrm{m} 2 . m_{2}$ refers to the luminance adaptation factor. $\mathrm{V}(\lambda)$ refers to the value of scotopic spectral sensitivity function. Figure 5 shows $\mathrm{V}(\lambda)$ and $\mathrm{V}^{\prime}(\lambda), \mathrm{V}^{\prime}(\lambda)$ is the curve of scotopic, and $\mathrm{V}(\lambda)$ is the curve of photopic. $V^{\prime}\left(\lambda_{0}\right)=683 / 1700$. $L_{\text {mes }, n}$ refers to the mesopic luminance. $L_{\mathrm{SPD}}(\lambda)$ refers to $L_{\mathrm{TSPD}}(\lambda)$ and $L_{\mathrm{BSPD}}(\lambda)$, respectively. The value of $\mathrm{S} / \mathrm{P}$ refers to scotopic to photopic luminous flux ratios of targets.

3.3. $C$. $C$ is calculated by (1). The calculation process of $C$ is shown in Figure 6. $C$ of different colours of targets is shown in Figure 7. We assume that the probability of each colour of targets appearing in the tunnel is the same. We assume that the probability of each colour of targets appearing in the tunnel is the same. In order to discuss the relationship between CRI2012 and contrast, Figure 8 shows the average $C$ of eight colours which are normalized.

As shown in Figure 7, $C$ is affected by the CRI2012 and CCT. Under a certain CCT, $C$ and CRI2012 show a positive correlation trend in most cases. Under a certain CRI2012, C and CCT show a negative correlation trend in most cases. When the colour is considered, except for black and blue, the law between the change of CRI2012 and CCT and the change of contrast is basically the same as the above law. Some colours at high CCT do not show law. This may involve indepth optical problems. This paper mainly discusses driving safety in the tunnel, and the complex optical problems are not considered. However, the calculation results are not completely consistent with the actual condition, and it still needs experimental verification.

\section{Experiment}

In order to test the real impact of different CRI2012s on human vision, we designed an experiment to measure the reaction time of human eyes. Three CCTs $(2800 \mathrm{~K}, 4500 \mathrm{~K}$, $6400 \mathrm{~K})$, four CRI2012s $(55,65,75,85)$, and eight colours were selected. 30 observers participated in the experiment.

4.1. Experimenter. In this experiment, there were $30 \mathrm{ob}-$ servers, 19 males, and 11 females. They are all qualified to drive cars, and Shintaro Ishihara's colour vision is normal.

4.2. Experimental Parameters. Three CCTs (2800k, 4500k, and 6400k), four CRI2012 (55, 65, 75, and 85), and eight targets of different colours are selected in the experiment. LED cube is used as the light source. The SPD of LED cube and ambient luminance settings are the same as in Section 3.1 .

Landolt chart is selected in the experiment as the observation target, also named " $C$ " visual chart. Eight targets of different colours, which are the same as those in Section 3.1, are selected. As shown in Figure 8, the orientation of " $C$ " is random to prevent the subjects from remembering the object orientation and affect the experimental results. The outer diameter of the target ' $C$ ' was $20 \mathrm{~mm}$. Preliminary experiments prove that $20 \mathrm{~mm}$ is the most suitable.

4.3. Experimental Device. Figure 9 shows the schematic diagram of the experimental device. The experiment was carried out in a simulated tunnel. The simulated tunnel is the same proportion as the real tunnel. The material of the inner wall is the same as that of the real tunnel. The LED cube is $1 \mathrm{~m}$ higher than the experimental platform, and the horizontal distance between the two LED cube is $0.5 \mathrm{~m}$. The horizontal distance between the blackboard and observation window is $3 \mathrm{~m}$. As a simulated pavement surface, the experimental platform is painted with asphalt colour similar to the asphalt pavement, to restore the internal environment of the tunnel 


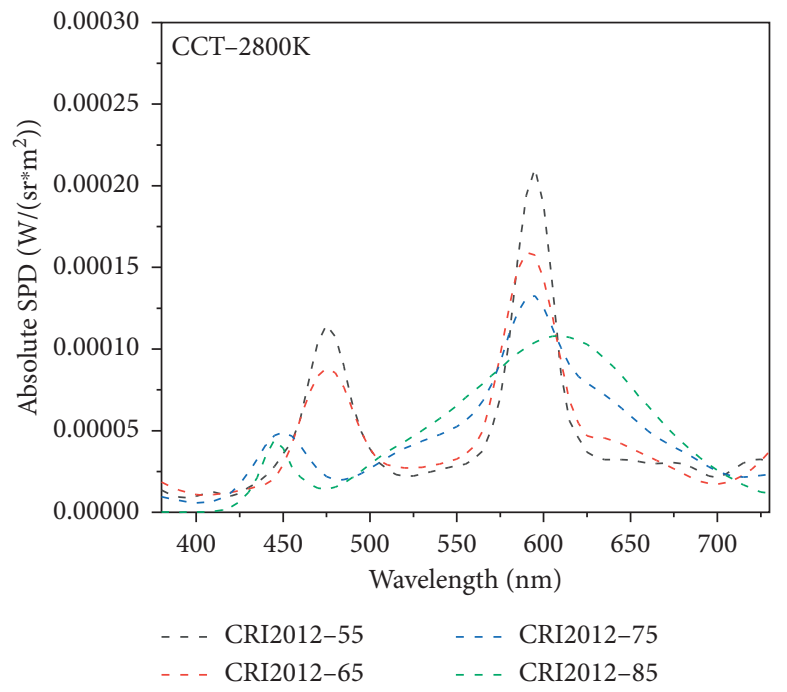

(a)

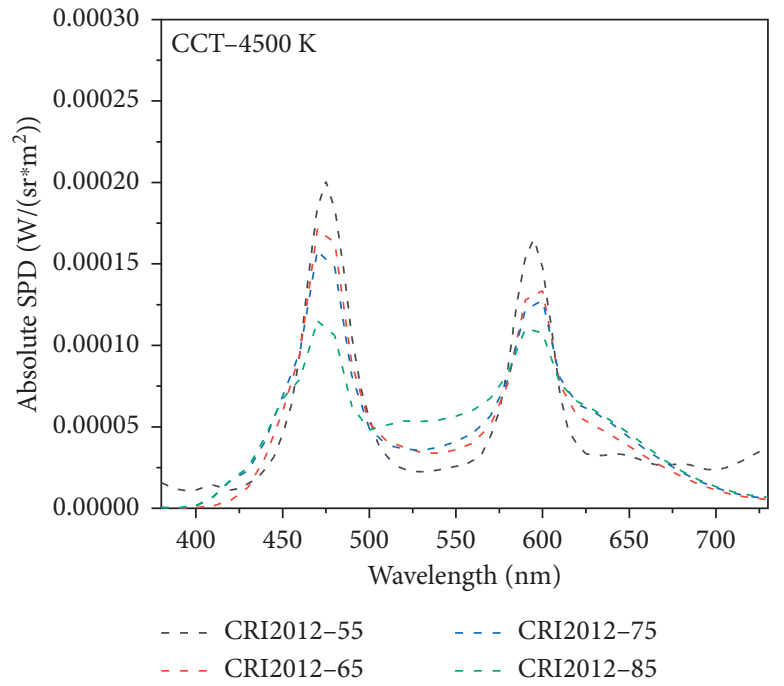

(b)

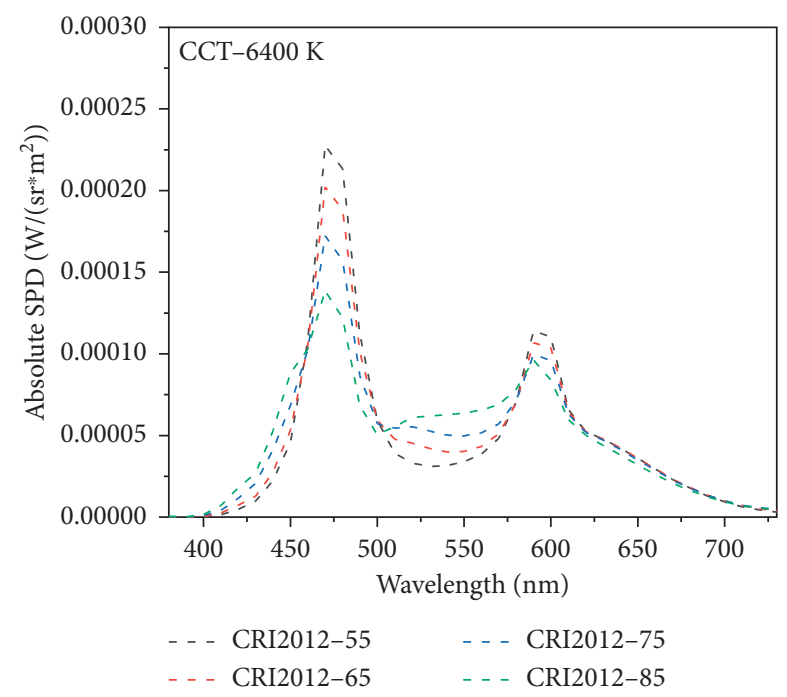

(c)

FIGURE 1: Relative SPDs of LEDs with different CRI2012s and CCTs, measured by Spectrometer I1-pro.

TABLE 1: Simulated real parameters of 12 lighting conditions in the tunnel.

\begin{tabular}{cccc}
\hline \multicolumn{2}{c}{$\begin{array}{c}\text { Experiment parameter } \\
\text { CCT }\end{array}$} & \multicolumn{2}{c}{ Actual value } \\
\hline \multirow{4}{*}{$2800 \mathrm{~K}$} & 55 & CCT & CRI2012 \\
& 65 & 2782 & 57 \\
& 75 & 2894 & 65 \\
& 85 & 2760 & 76 \\
$4500 \mathrm{~K}$ & 55 & 2743 & 86 \\
& 65 & 4485 & 55 \\
& 75 & 4653 & 66 \\
& 85 & 4518 & 75 \\
$6400 \mathrm{~K}$ & 55 & 4536 & 85 \\
& 65 & 6482 & 55 \\
& 75 & 6413 & 64 \\
& 85 & 6479 & 76 \\
& & 6408 & 84 \\
\hline
\end{tabular}

as much as possible. Figure 10 shows a panoramic view of the simulated tunnel.

4.4. Procedure Specification. Firstly, the observer held the timer and sat in front of the observation window. Before hearing the begin timing, the observer was asked not to look directly at the blackboard, but to saccade the pavement.

Secondly, the observers got orders began to search for the target on the blackboard and pressed the timer. When the observer finds the target and fully sees the direction of the " $C$," the timer is pressed again to stop timing, and the time obtained is the reaction time. And, the observers were asked to identify the colour of target in first experiment. 


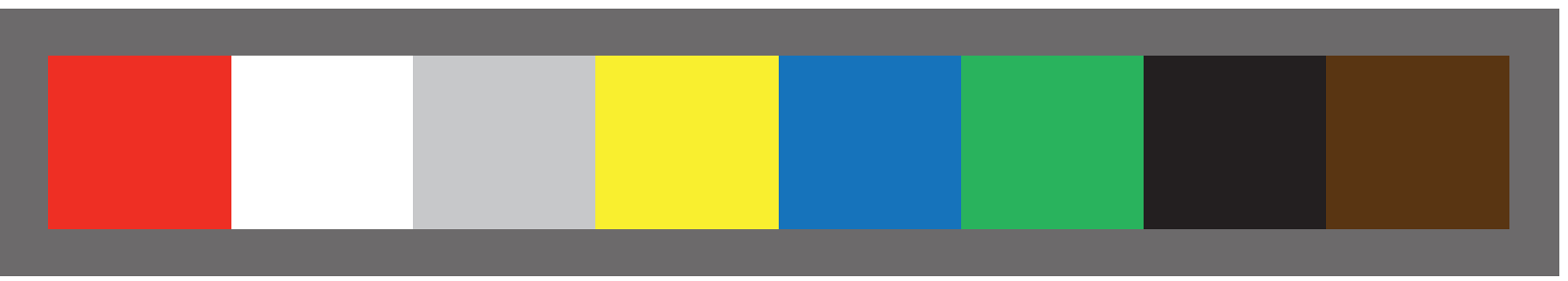

Figure 2: Eight colours.
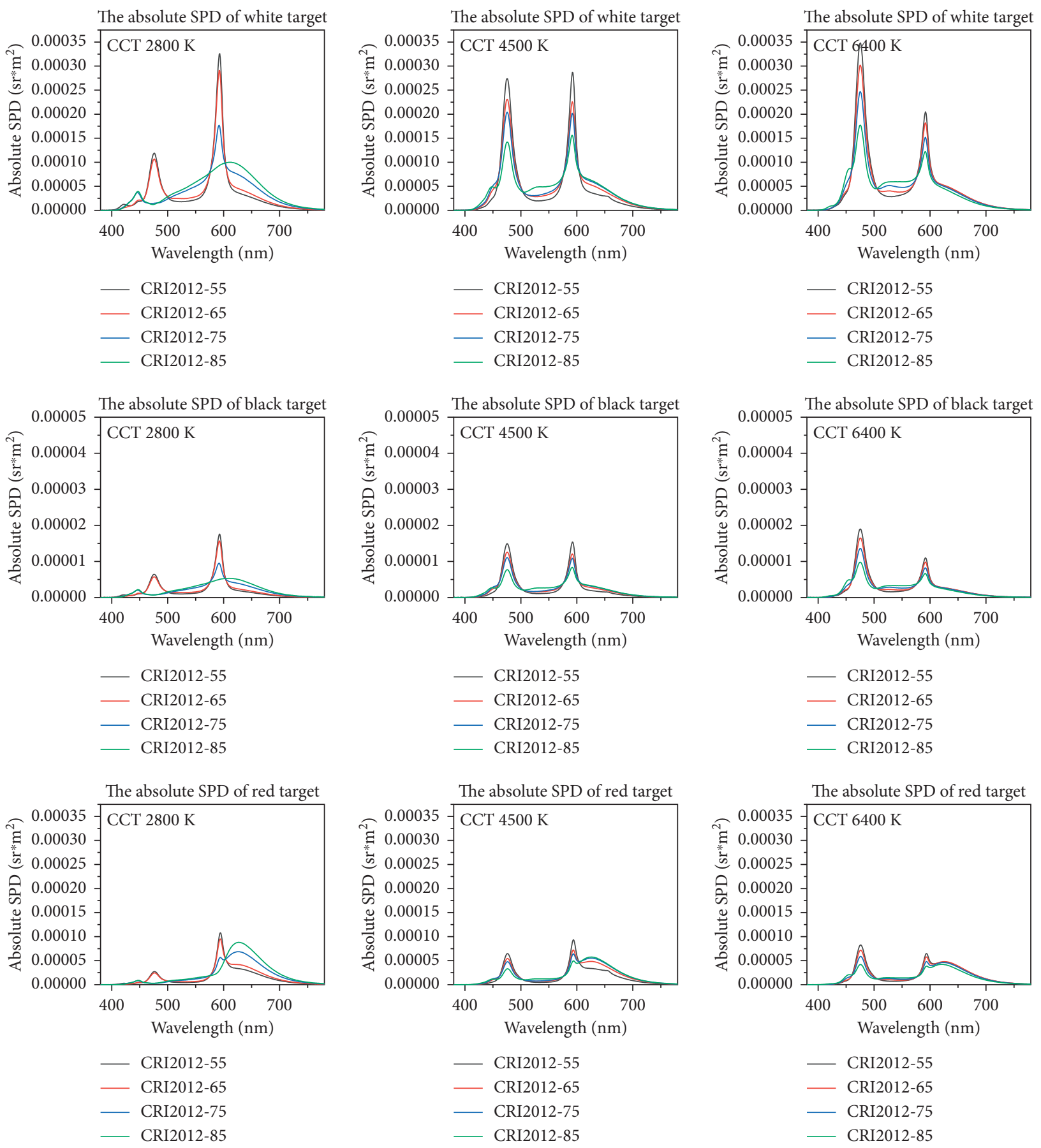

(a)

Figure 3: Continued. 
The absolute SPD of yellow target

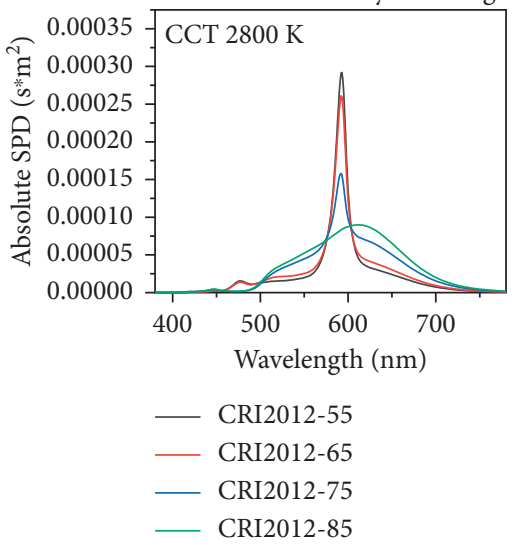

The absolute SPD of silver target

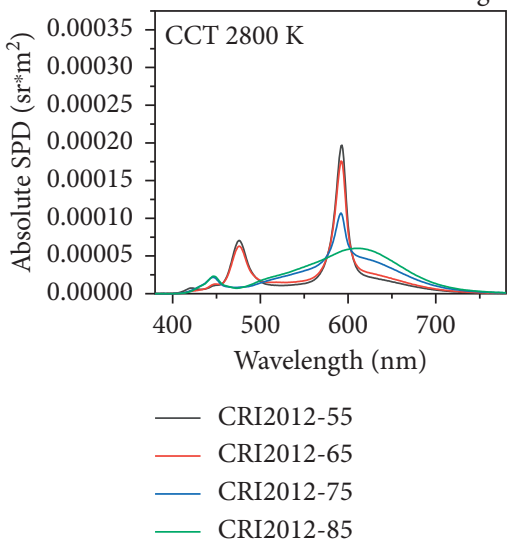

The absolute SPD of blue target

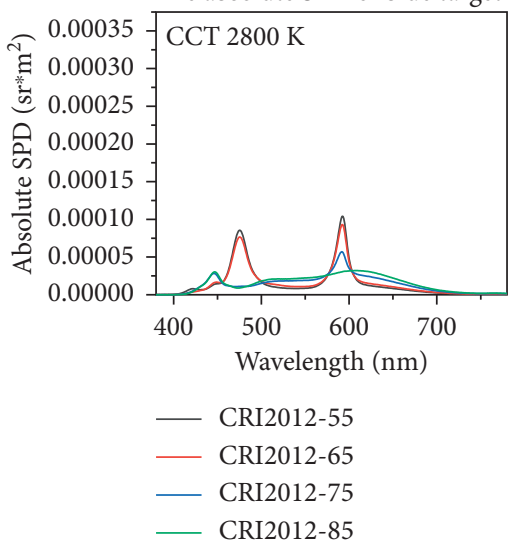

The absolute SPD of yellow target

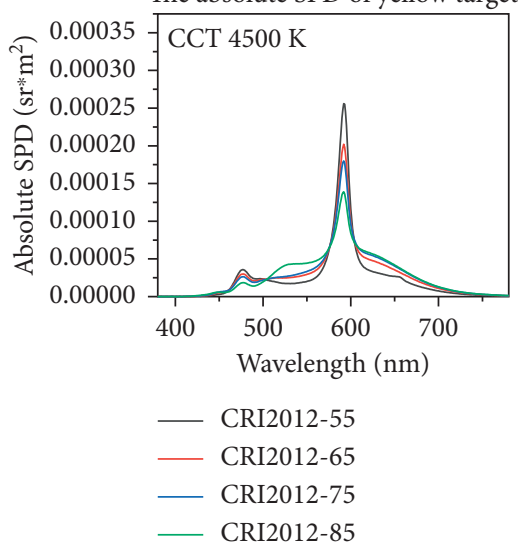

The absolute SPD of silver target

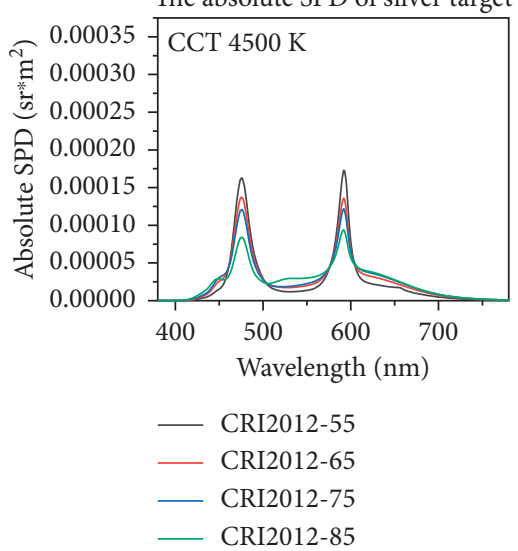

The absolute SPD of blue target

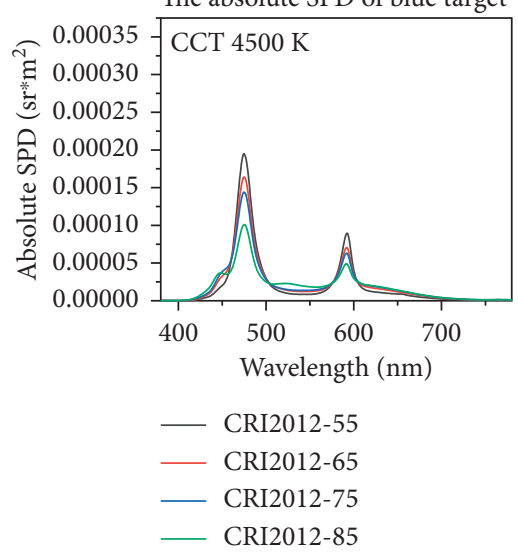

(b)
The absolute SPD of yellow target

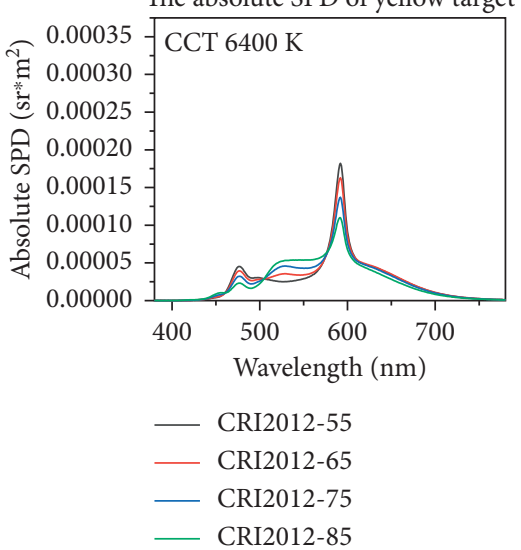

The absolute SPD of silver target

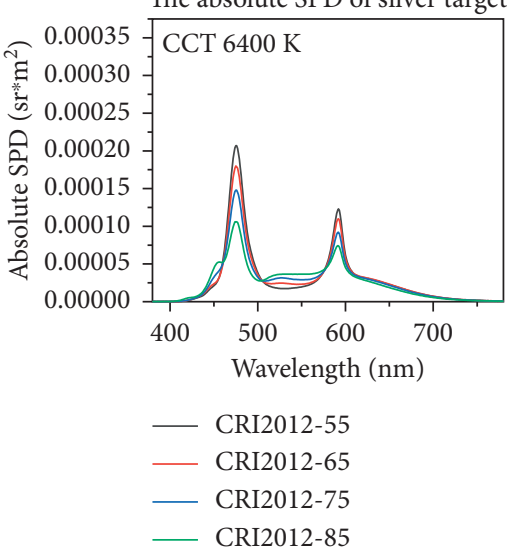

The absolute SPD of blue target

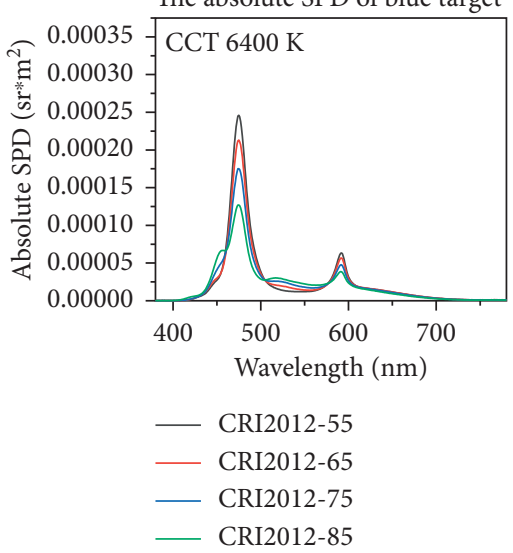

Figure 3: Continued. 


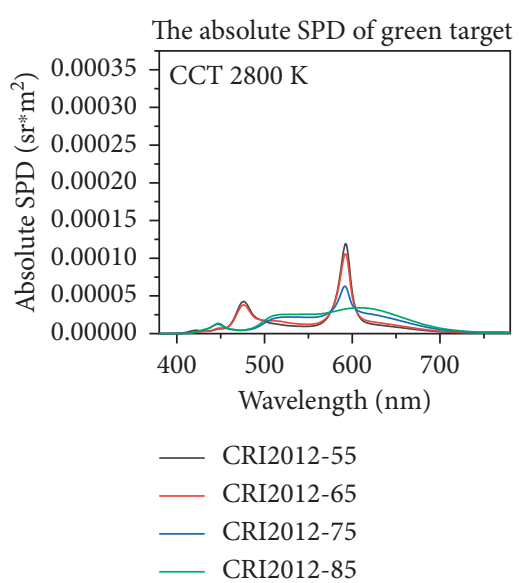

The absolute SPD of brown target

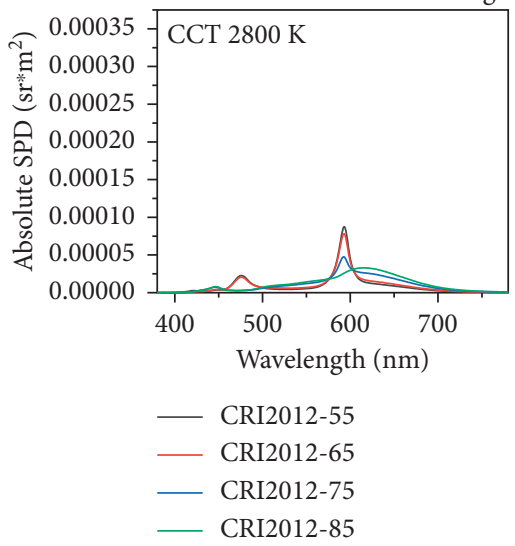

The absolute SPD of background

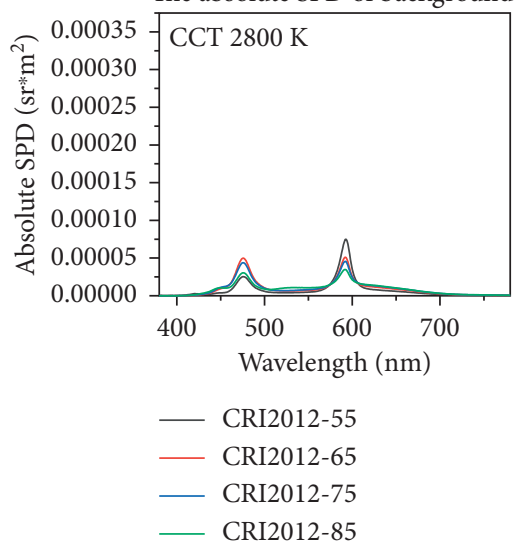

The absolute SPD of green target

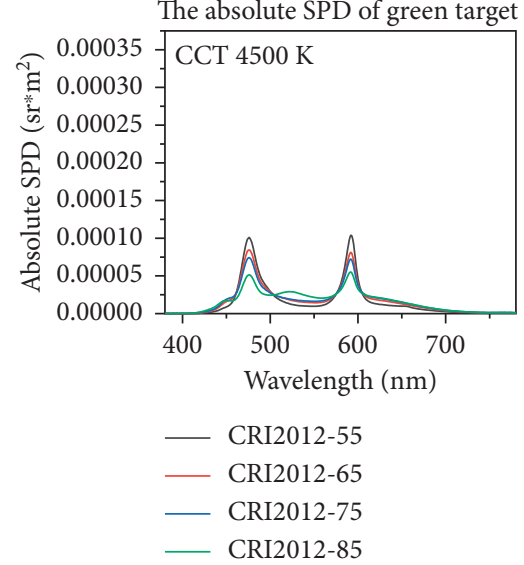

The absolute SPD of brown target

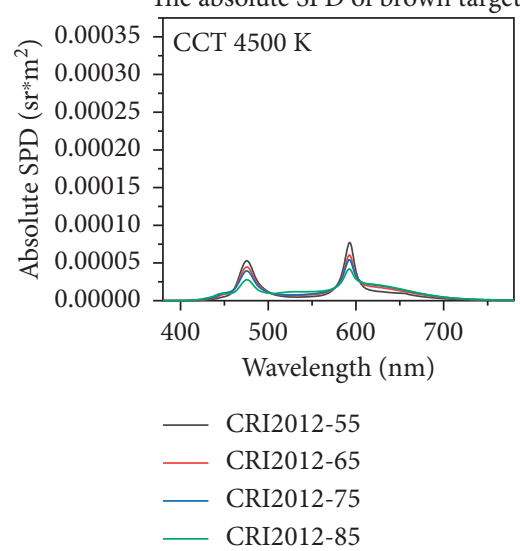

The absolute SPD of background

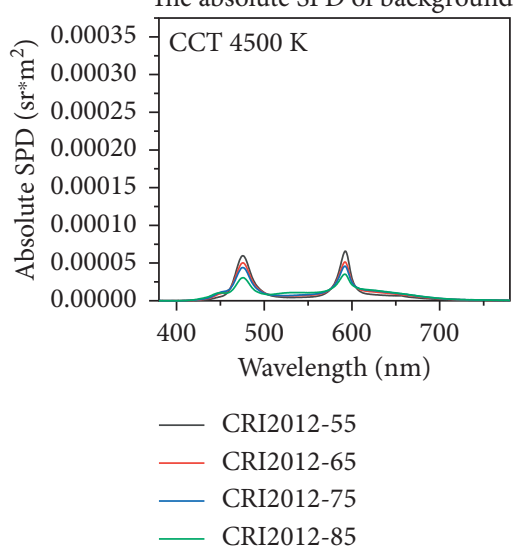

The absolute SPD of green target

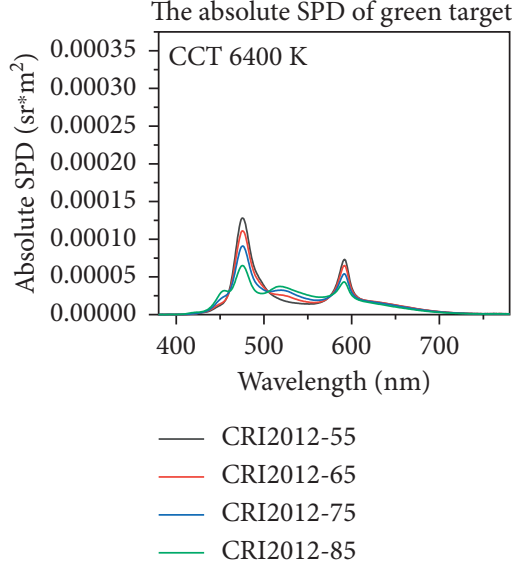

The absolute SPD of brown target

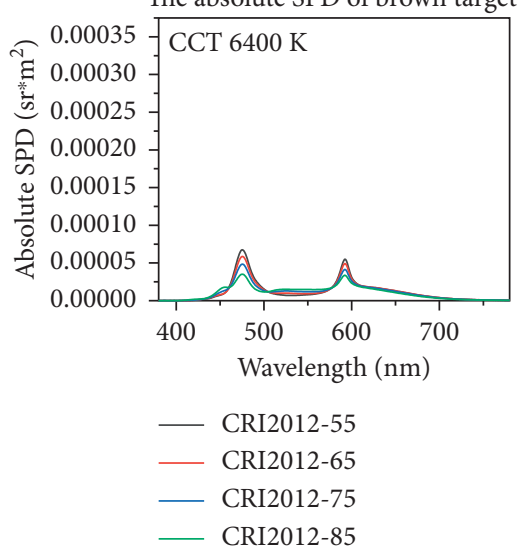

The absolute SPD of background

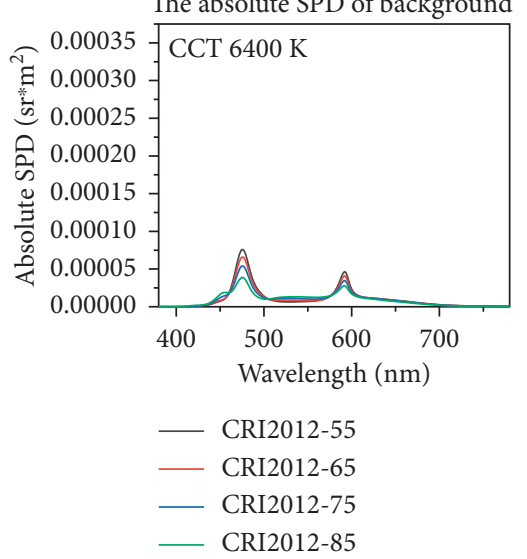

(c)

FIgUre 3: Absolute SPD of targets with different CRI2012s and CCT.

Thirdly, the experimenter changed the CCT and CRI2012 of LED cube, colour, position, and direction of the targets, and repeat the above steps again until each kind of light environment and colours have completed the experiment. Figure 9 shows the real perspective of the observers.

The colour of the indicator will carry useful information in the real tunnel, so it is fast and accurate to discriminate the colour is conducive to the driver to quickly understand the road information. So, we designed a colour discrimination experiment based on the reaction time experiment. Considering majority of observers cannot accurately identify the colour when the CRI2012 of the LED is 55, so in the colour discrimination experiment, the CRI2012 of the LED is set to 3 CRI2012s $(65,75$, and 85) and 3 CCTs $(2800 \mathrm{~K}, 4500 \mathrm{~K}$, and $6400 \mathrm{~K})$. The time required for the observer to discriminate colours under different CRI2012s and CCTs was measured. 


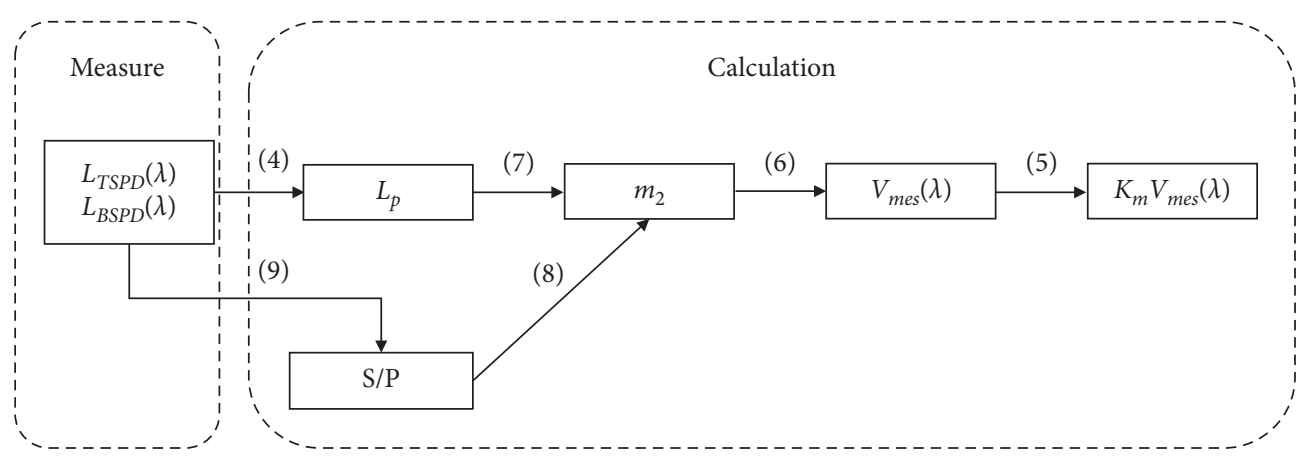

FIgURE 4: The calculation process of $k_{m} V_{\text {mes }}(\lambda)$.

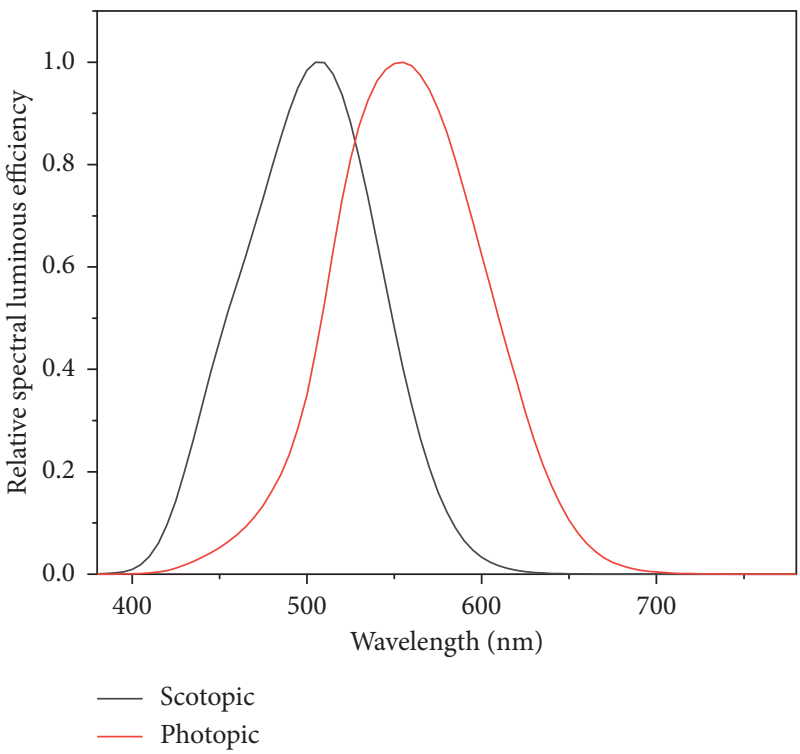

FIGURE 5: Relative spectral luminous efficiency curves of photopic and scotopic.

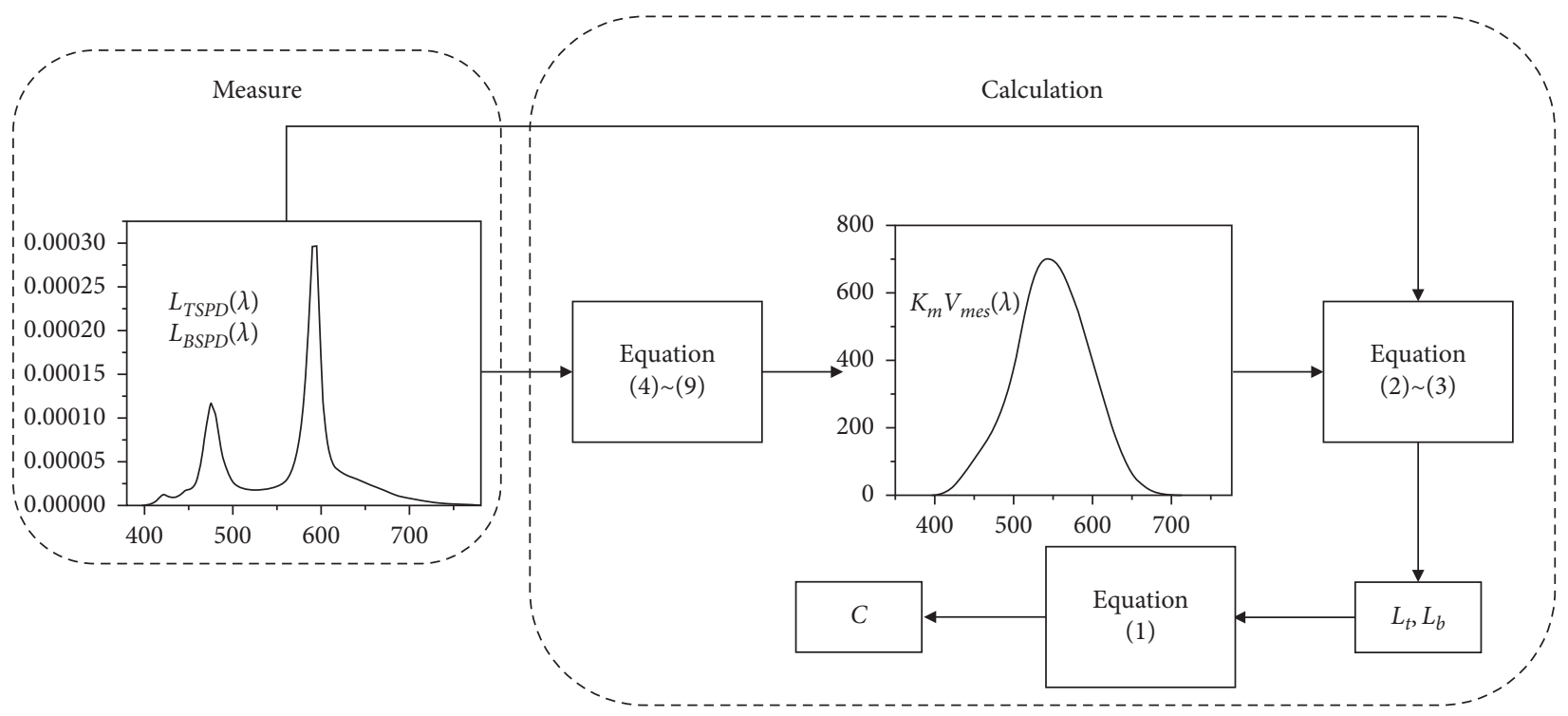

FIGURE 6: The calculation process of $C$. 


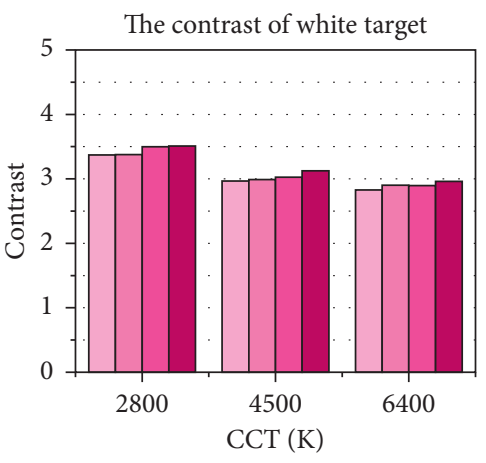

CRI2012-55

CRI2012-65

CRI2012-75

CRI2012-85

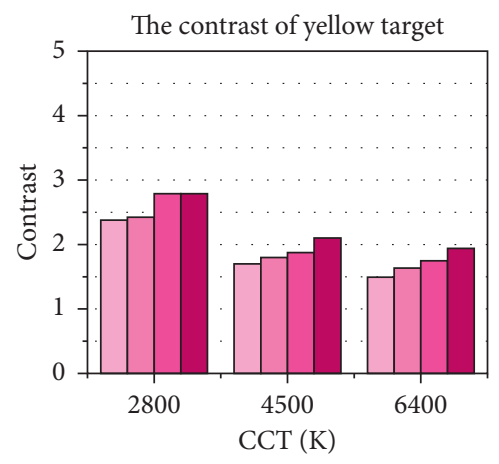

CRI2012-55

CRI2012-65

CRI2012-75

CRI2012-85

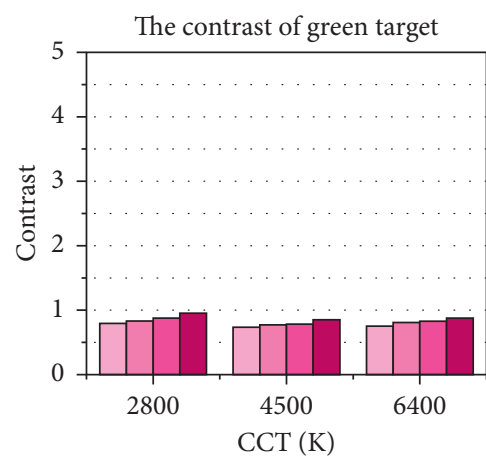

CRI2012-55

CRI2012-65

CRI2012-75

CRI2012-85

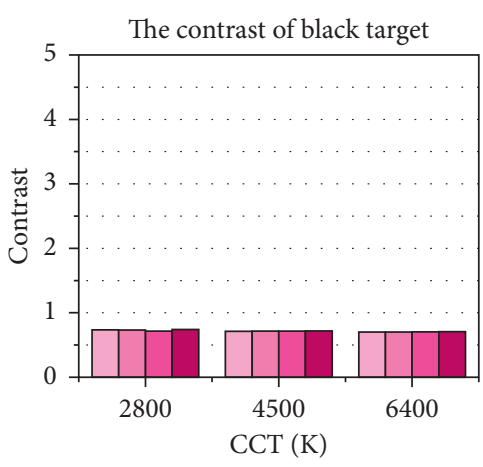

CRI2012-55

$\square$ CRI2012-65

CRI2012-75

CRI2012-85

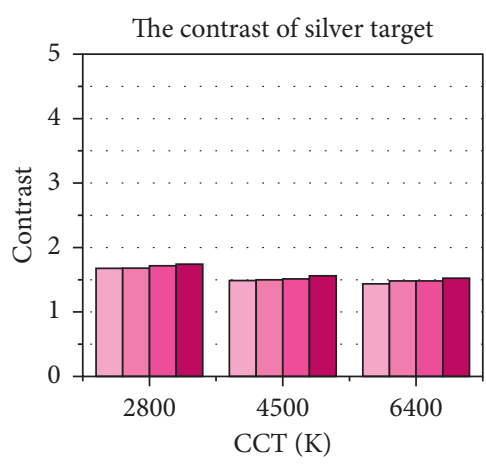

CRI2012-55

$\square$ CRI2012-65

CRI2012-75

CRI2012-85

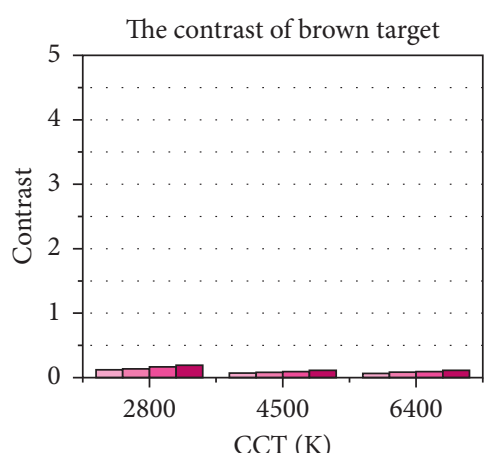

CCT $(\mathrm{K})$

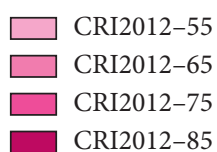

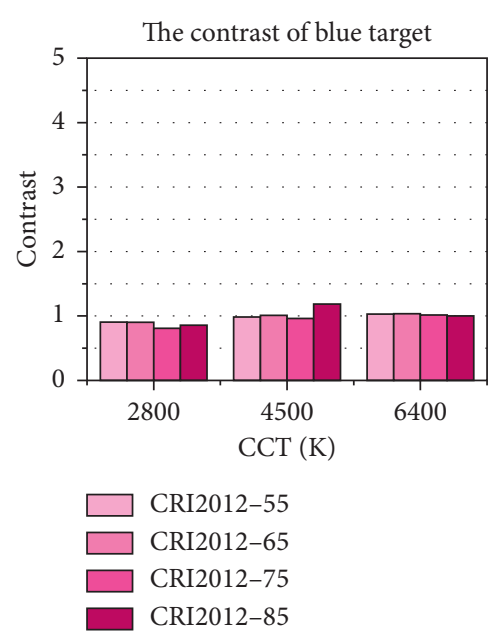

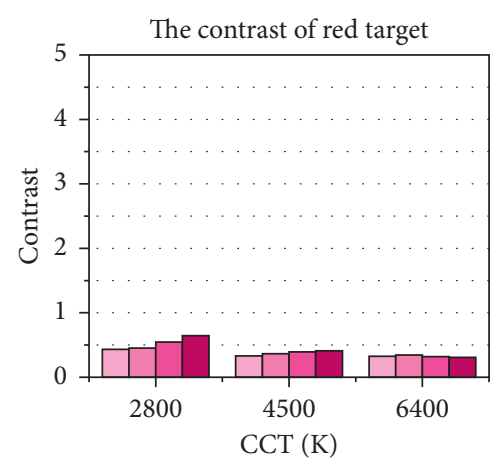

CRI2012-55

CRI2012-65

CRI2012-75

CRI2012-85

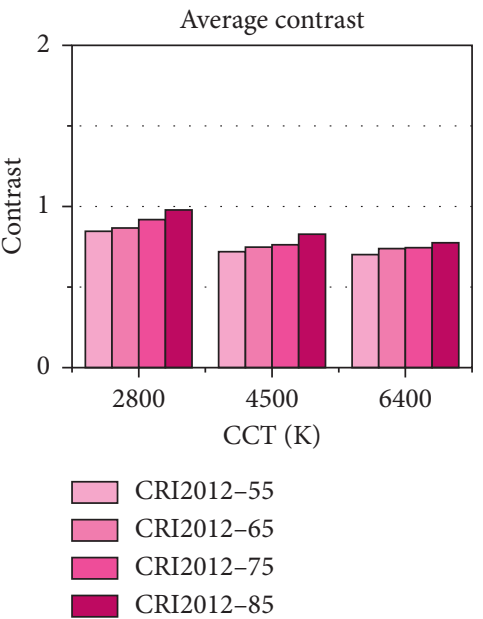

FIGURE 7: The calculation results of C.

In order to reduce the experimental error, the observers are required to perform the experiment three times to familiarize with the process, and recording of the results is not needed. After each experiment, the observer is required to rest for 3 minutes to prevent the interference of visual fatigue on the experimental results. And, the observers can also select and play music or radio during the experiment according to their usual driving habits.
4.5. Experimental Feasibility Analysis. Although there are some differences between the laboratory and the real tunnel environment, such as the luminance in the tunnel, the reflection spectrum of obstacles, and the distance of observing obstacles, however, this paper studies the law between CRI2012 and reaction time; the differences will not affect the intrinsic law between CRI2012 and reaction time, so the results in the laboratory will still contribute to the tunnel 


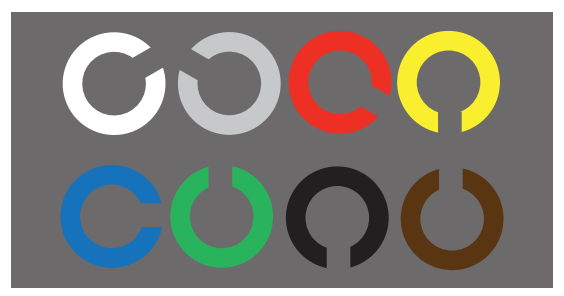

Figure 8: Targets used in the experiment with different colours.

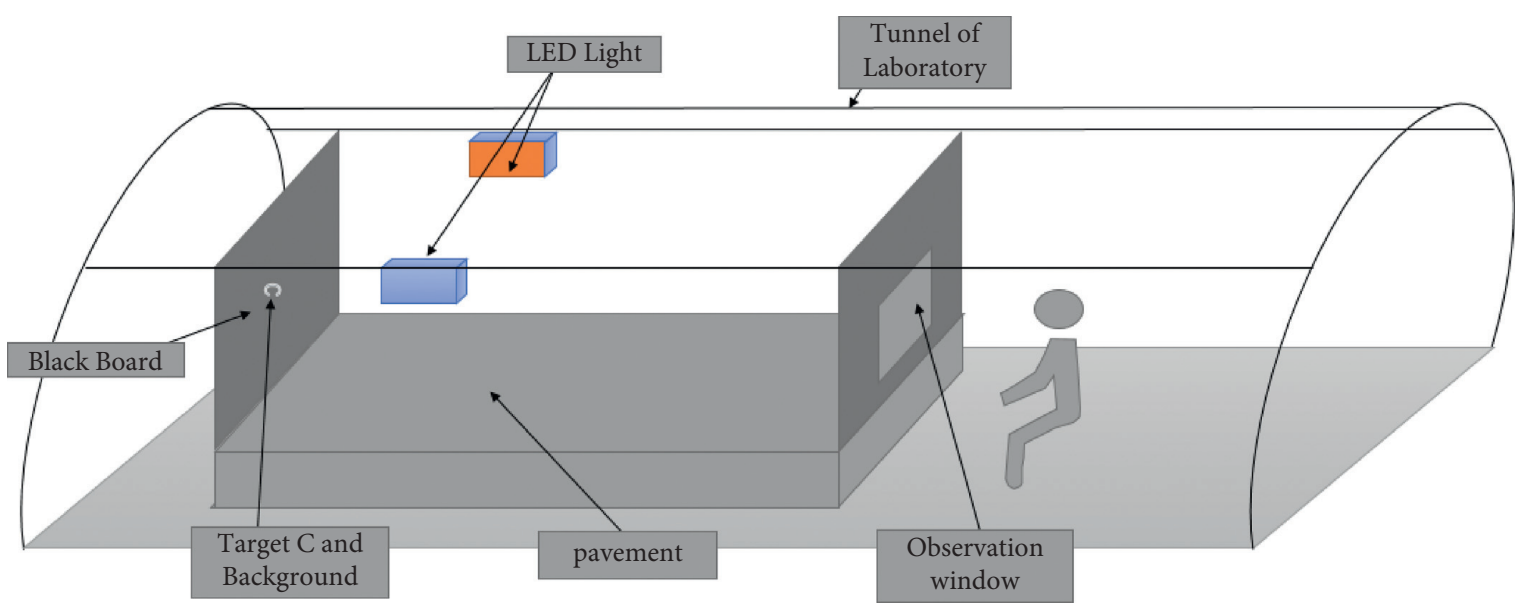

Figure 9: Real scene of the simulated tunnel in the laboratory.

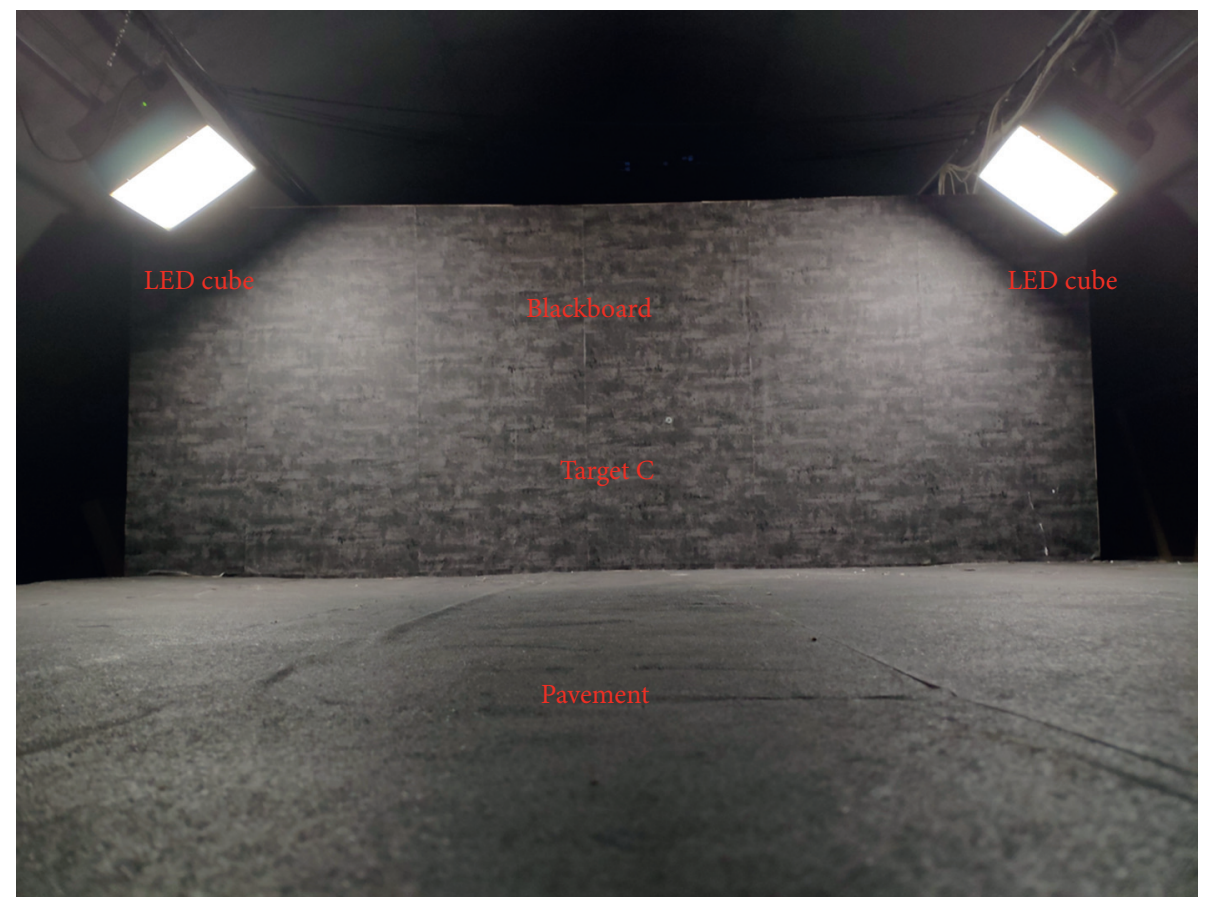

Figure 10: Schematic diagram of the simulated tunnel.

lighting. In addition, changing the light conditions is easy in the laboratory, which helps to reduce the error. In a real highway tunnel, it is almost impossible to change the lighting conditions. Figure 11 shows the visual of the actual tunnel interior zone and the visual of the observers in the experiment to illustrate the feasibility of the experiment. This method can accurately measure the reaction time of human eyes in the tunnel. 


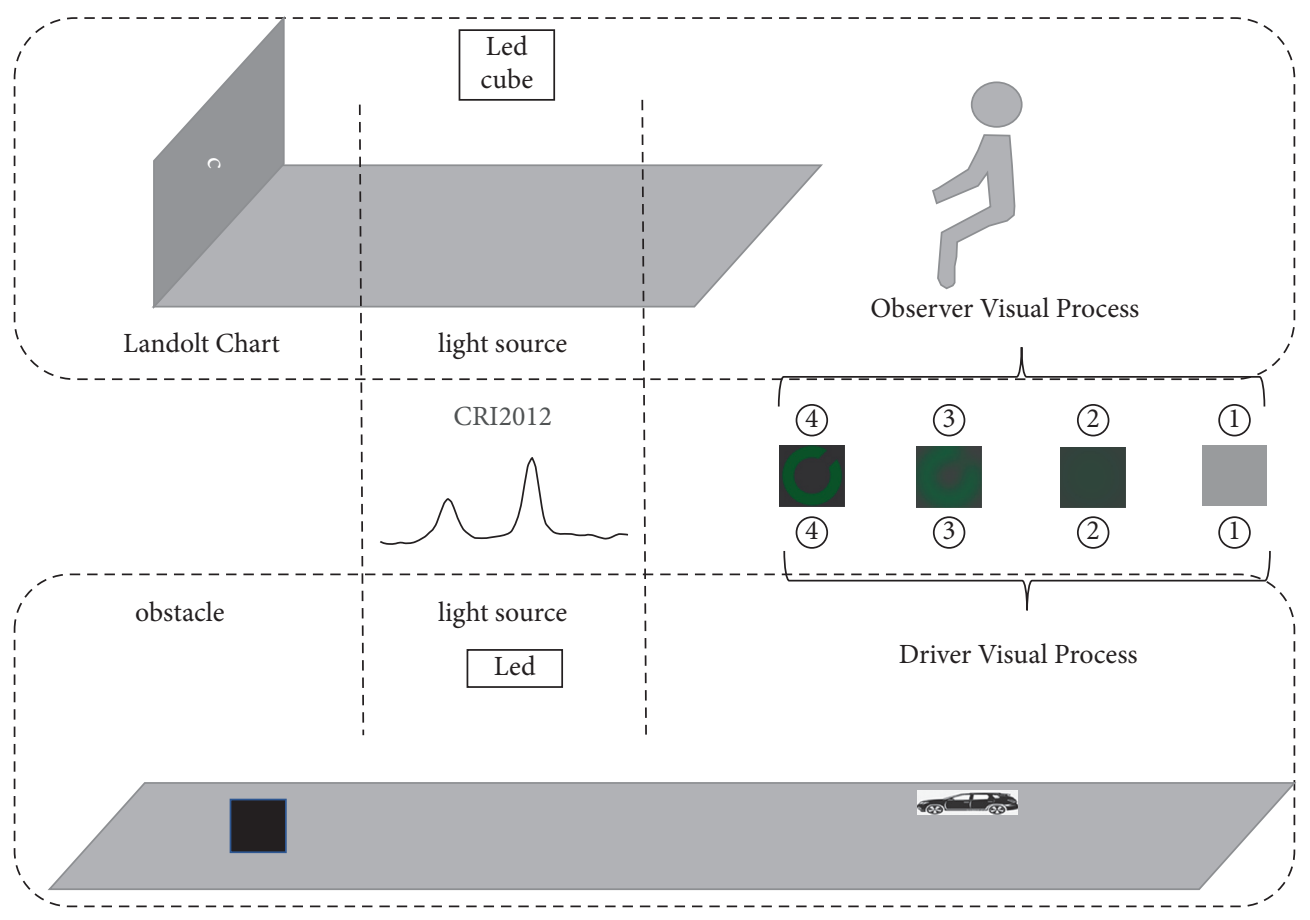

FIGURE 11: Comparison of the visual process in laboratory and visual process in real tunnels.

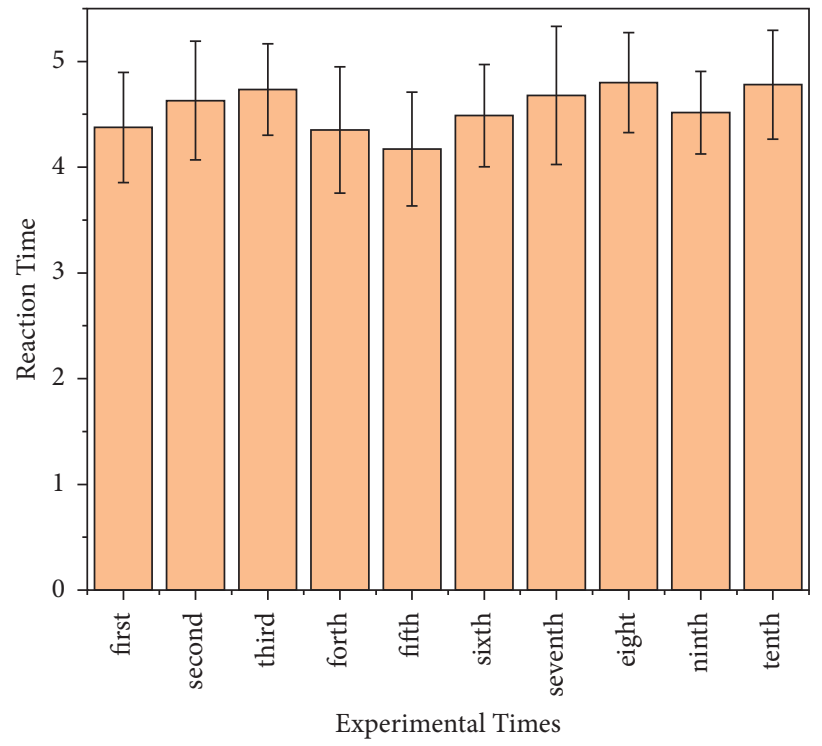

Figure 12: Ten repetitions' reaction time of ten observers.

\section{Results and Discussion}

To measure the error of the experiment, ten of thirty observers were asked to perform the preliminary experiment 10 times using the black target and LED cubes with CRI2012 of 75 and CCT of $4500 \mathrm{~K}$. The reaction time of the ten observers is shown in Figure 12. There was no correlation between the number of experiments and the reaction time.

Figures 13 and 14 show the average reaction time of all observers under different CRI2012s and CCTs. Figure 13 shows the average reaction time of observers to the eight colours of the target. The reaction time decreases with the increase of CRI2012, which agrees with the theoretical results in Section 3. In Figure 14, the experimental data of most colours showed that the reaction time decreased with the increase of CRI2012. The reaction time of yellow, white, and silver is too short due to the high contrast; therefore, the error is large. However, it is easy to see that high CRI2012 have a positive effect on shortening the reaction time. 


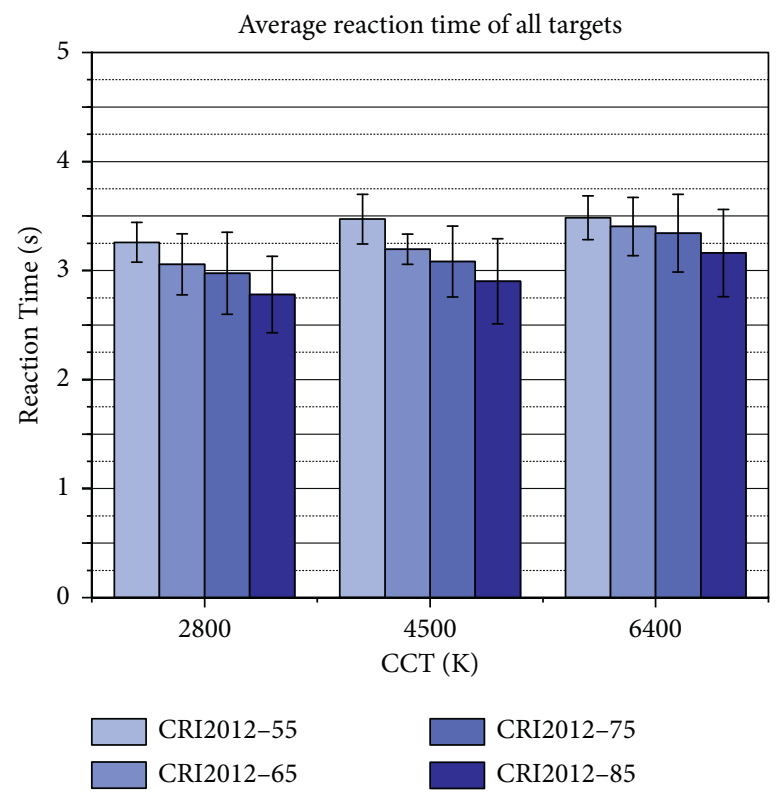

FIGURE 13: All colour's average reaction time under 12 lighting conditions.

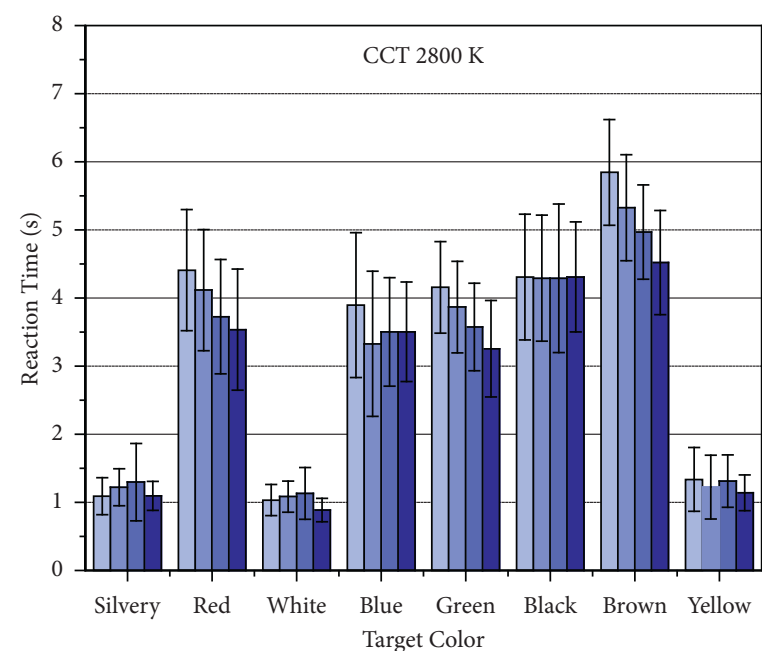

CRI2012-55

CRI2012-65

CRI2012-75

CRI2012-85

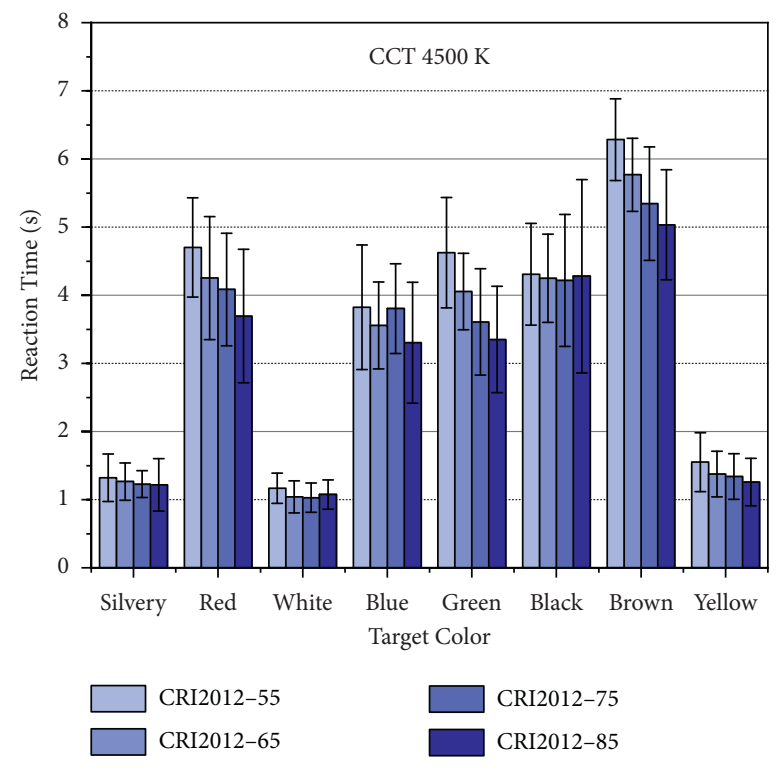

(b)

FIgURE 14: Continued. 


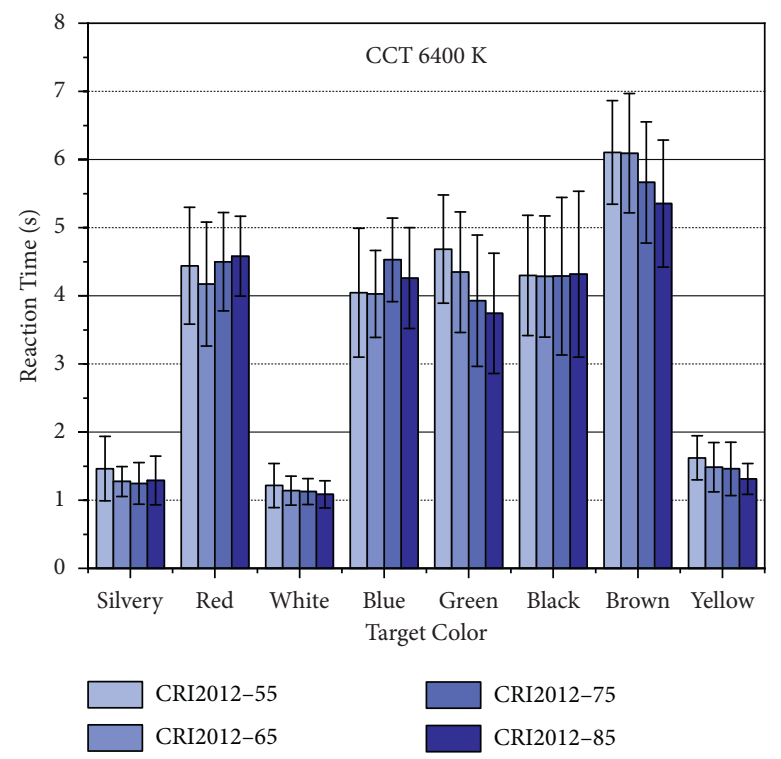

(c)

FIgURE 14: The reaction time of all observers under different CRI2012s and CCTs.

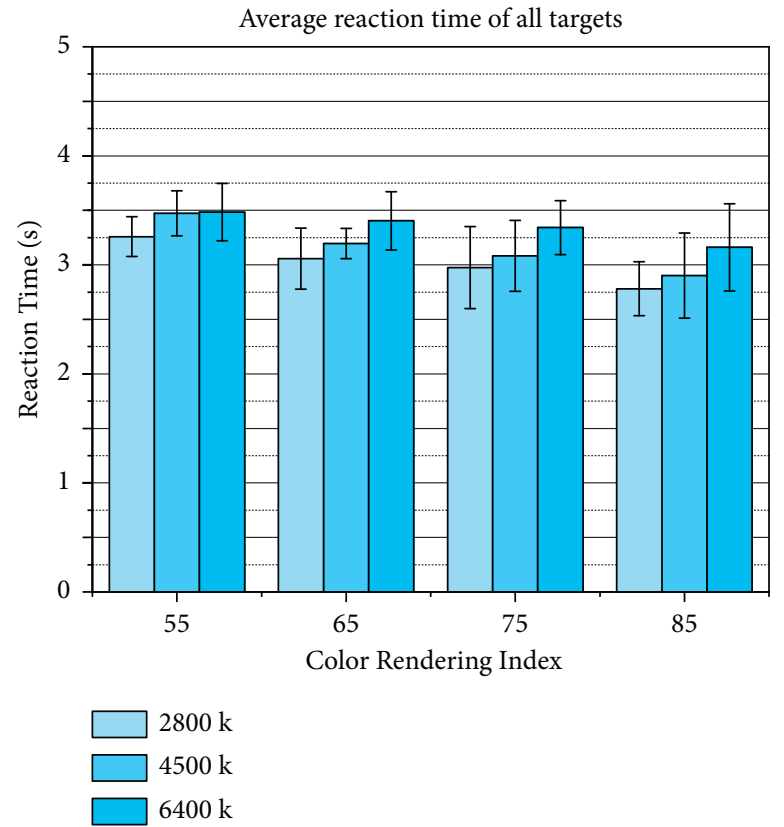

FIgURE 15: All colour's average reaction time under 12 lighting conditions.

Although this paper mainly studies the impact of CRI2012 on reaction time, the influence of CCT on reaction time is also considered. Figures 15 and 16 show the impact of CCT on the reaction time. Figure 15 shows the average reaction time of observers to the eight colours of the target. From the calculation results of the average value shown in Figure 17, the reaction time increases with the increase of CCT. In Figure 16, the experimental data of most colours showed that the reaction time decreased with the decrease of CCT.
The diffuse reflectance will have a greater impact on the contrast resolution of the human eyes, thereby affecting the reaction speed. Figure 18 shows the SPDs of eight targets with different colours in sunlight, the SPD of the background in sunlight, and the SPD of the sunlight measured by a Konica-Minolta CS2000. The results of the experiment showed that the diffuse reflectance of white, yellow, and silver was relatively high, and the reaction time of human eyes to these three colours was the least. Although the diffuse reflectance of red is higher than that of blue and 


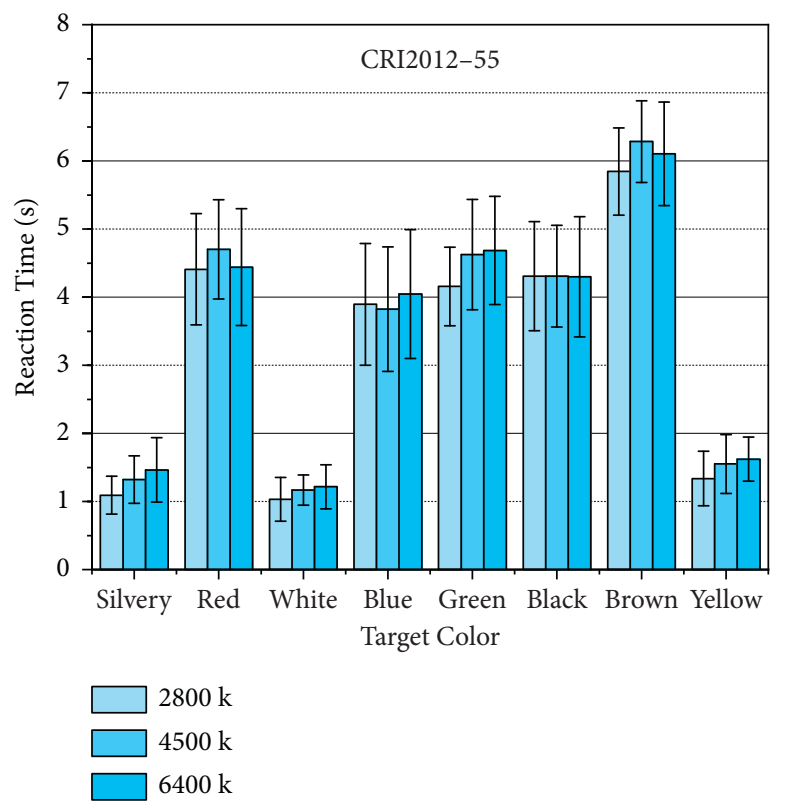

(a)

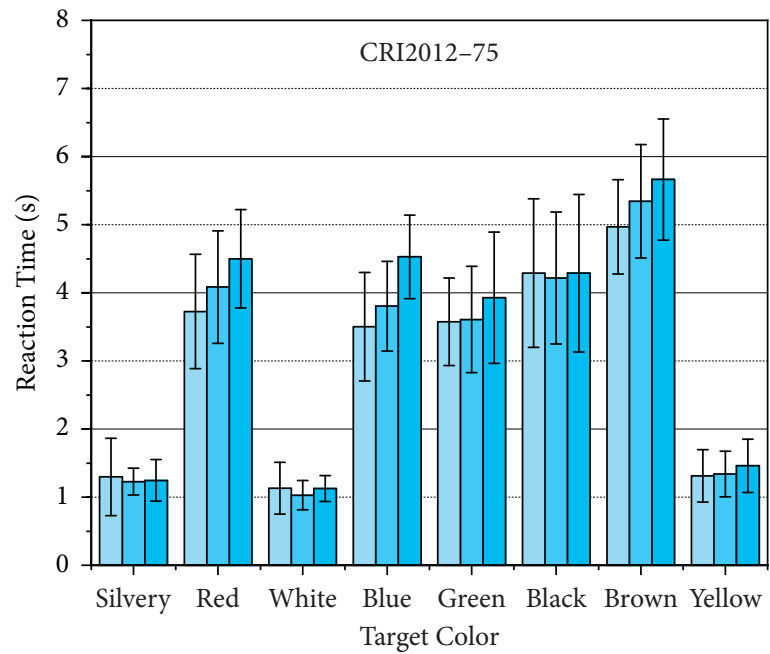

$2800 \mathrm{k}$

$4500 \mathrm{k}$

$6400 \mathrm{k}$

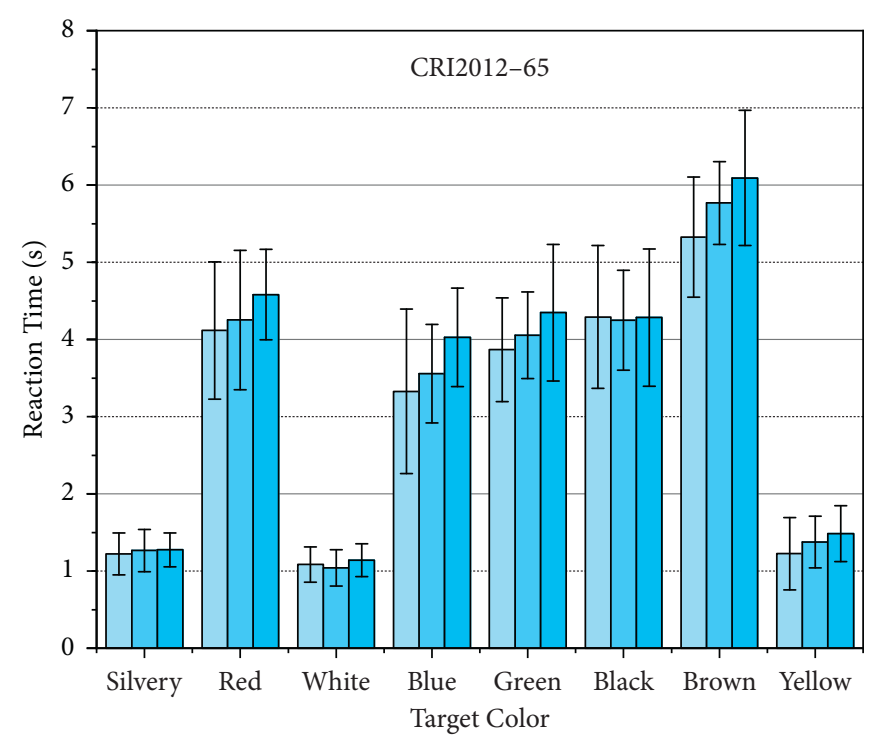

$2800 \mathrm{k}$

$4500 \mathrm{k}$

$6400 \mathrm{k}$

(b)

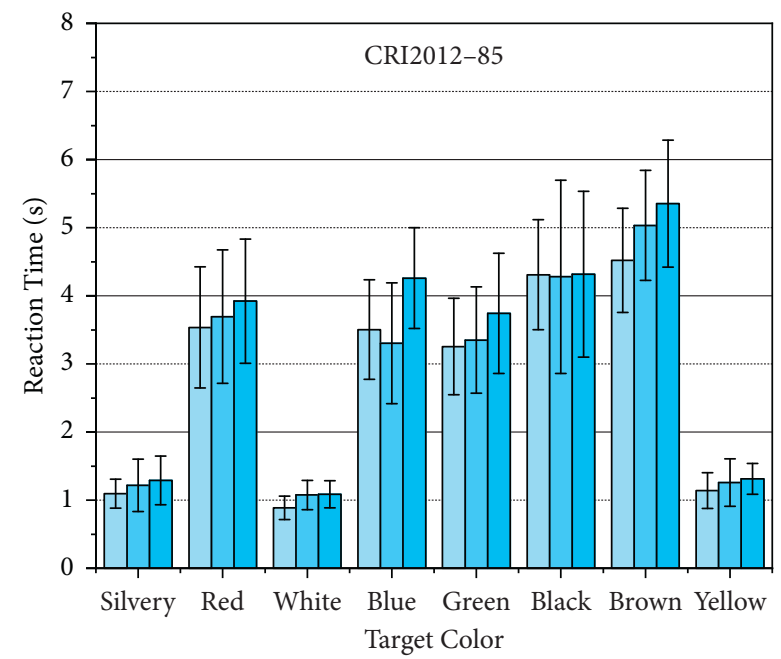

$2800 \mathrm{k}$

$4500 \mathrm{k}$

$6400 \mathrm{k}$

(c)

(d)

FIgURE 16: The reaction time of all observers under different CRI2012s and CCTs.

green and close to silver, it can be seen that the red target reflects red ray, and the silver reflects more evenly. The blue, green reflection spectrum components are mainly blue ray, while human eyes are more sensitive to blue light. Therefore, red, blue, and green had no difference in reaction time. Although the reflectance of black is lower than brown, it is far from the luminance of background, and the brown and background are too close, so it is difficult to be recognized.

Table 2 shows the significance analysis with reaction time as the dependent variable; the independent variable is CRI2012, CCT, and colour of targets. When the significance $p$ value of some independent variable and the dependent variable is less than 0.05 , it indicates that there is a significant correlation between the two variables. The smaller the value of $p$, the stronger the correlation between the two variables.

In Table 2, the correlation between colour of targets and reaction time is the strongest, followed by CRI2012, and finally CCT. The $p$ values of colour of targets, CCT, and CRI2012 were all less than 0.05 , so the significant 


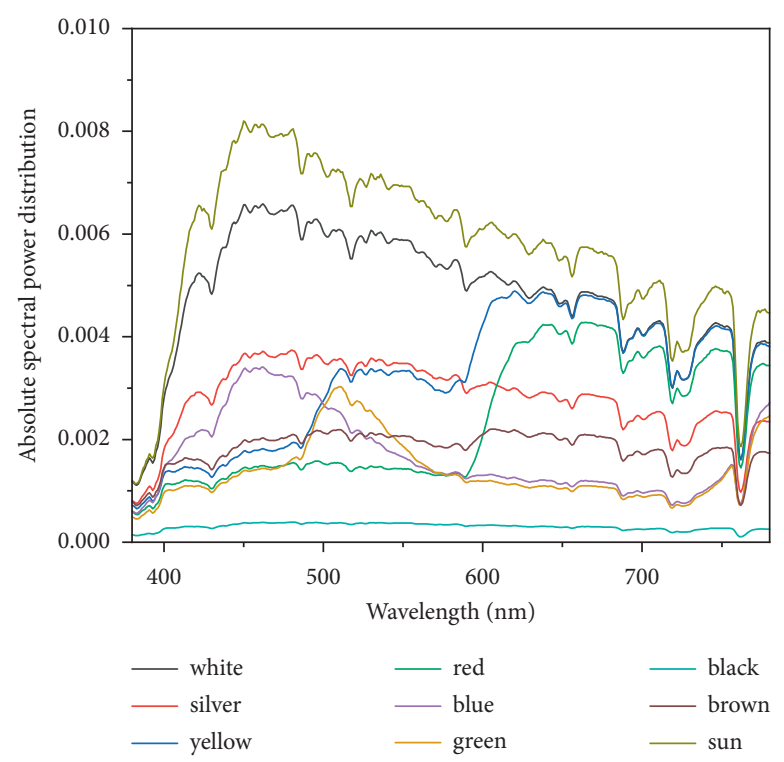

(a)

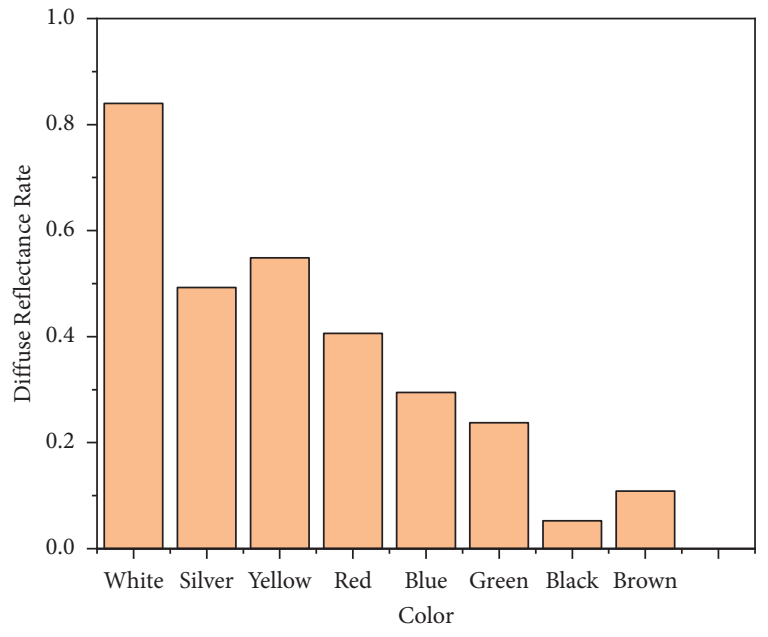

Figure 17: (a) The SPDs of eight targets with different colours of targets and backgrounds. (b) The diffuse reflectance of eight targets withdifferent colours.

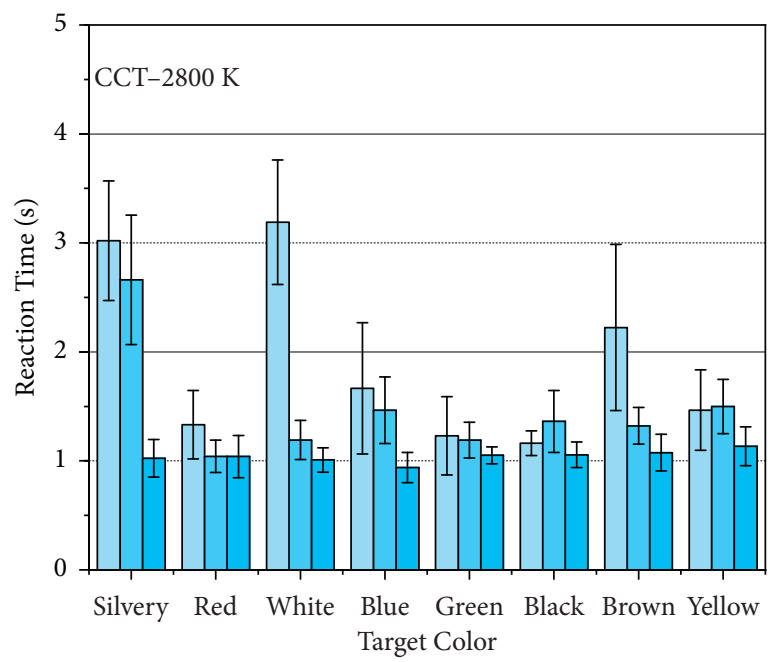

CRI2012-65

CRI2012-75

CRI2012-85

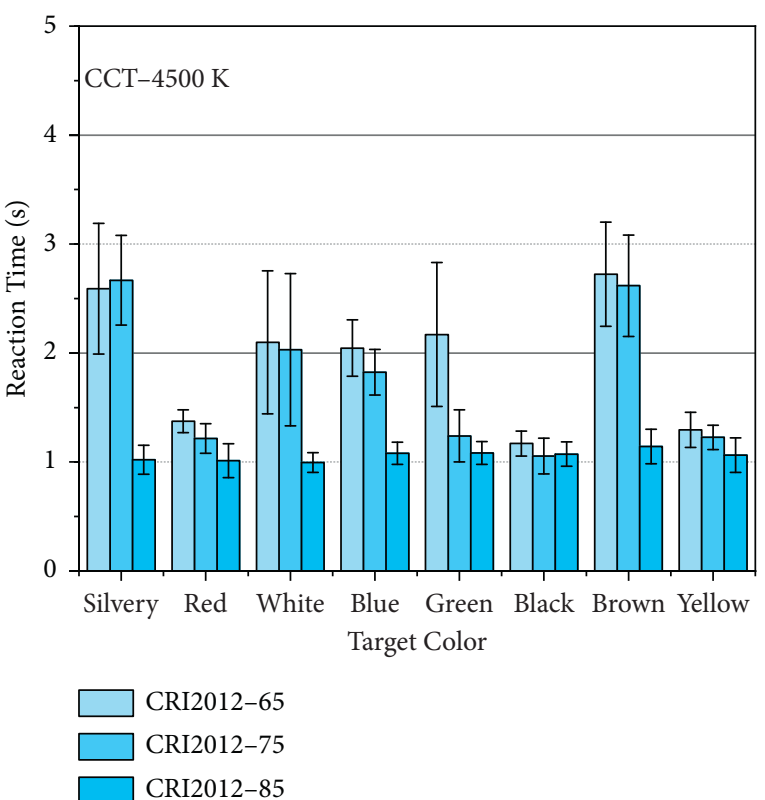

(b)

Figure 18: Continued. 


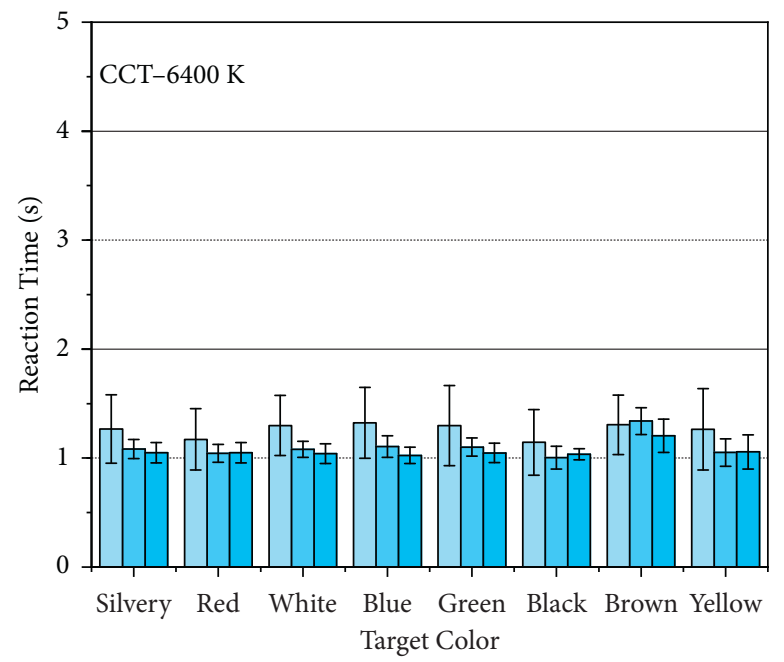

$\square$ CRI2012-65

CRI2012-75

CRI2012-85

(c)

FIgURE 18: The reaction time of all observers under different CRI2012s and CCTs.

TABLE 2: Correlation analysis of all experimental data.

\begin{tabular}{lr}
\hline Significance $(p)$ & Reaction time \\
\hline CRI2012 & $p=0.005$ \\
CCT & $p=0.011$ \\
Colour of target & $p<0.001$ \\
\hline
\end{tabular}

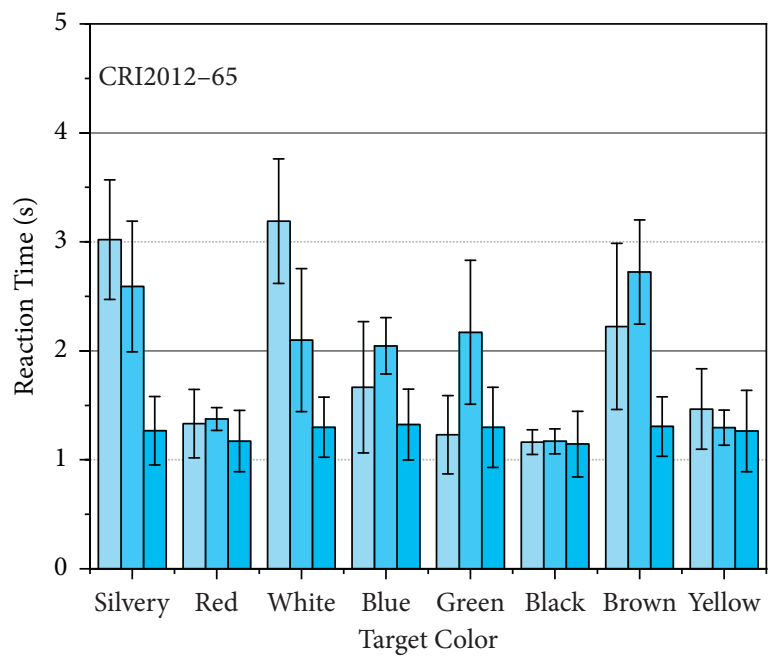

CCT- $2800 \mathrm{~K}$ $\square$ CCT- $4500 \mathrm{~K}$ $\square$ CCT-6400 K

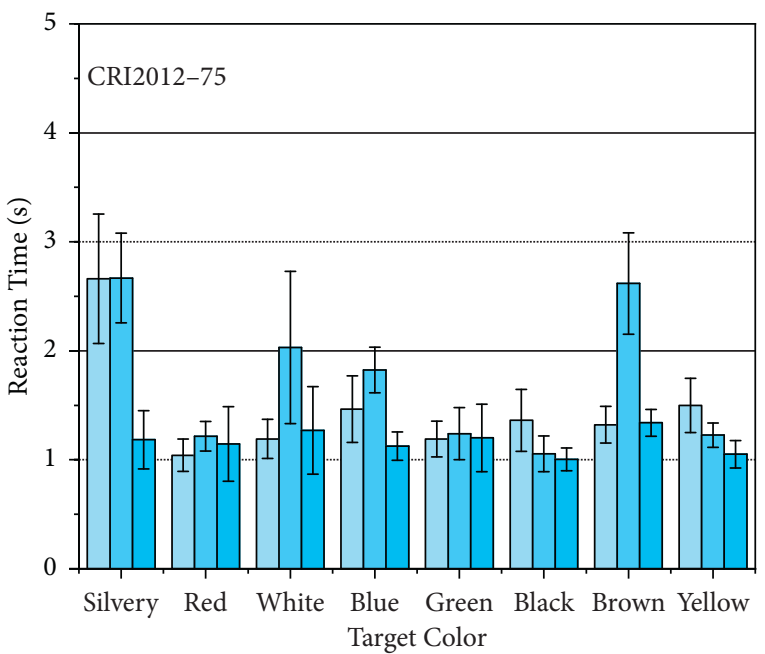

CCT $-2800 \mathrm{~K}$

CCT $-4500 \mathrm{~K}$

CCT- $6400 \mathrm{~K}$

(a)

FIgURe 19: Continued. 


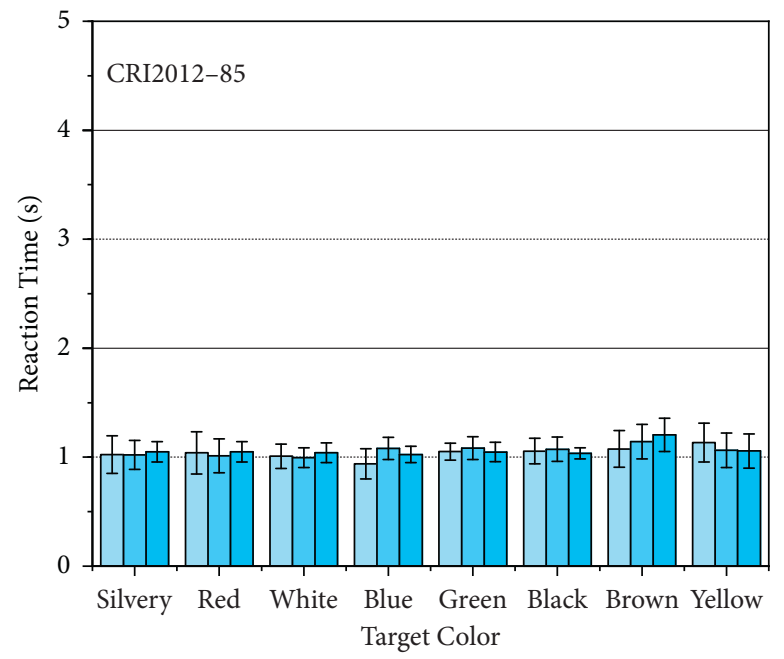

$$
\begin{aligned}
& \text { CCT }-2800 \mathrm{~K} \\
& \text { CCT }-4500 \mathrm{~K} \\
& \text { CCT }-6400 \mathrm{~K}
\end{aligned}
$$

(c)

Figure 19: The reaction time of all observers under different CRI2012s and CCTs.

correlation between the reaction time and the three factors is strong. However, only considering the impact of LEDs on reaction time, the impact of CRI2012 is greater than that of CCT.

In Figure 17, the experimental data of most colours showed that the colour discrimination time decreased with the increase of CRI2012. Especially, CRI2012 on reducing colour discrimination time has a significant effect when CCT is $2800 \mathrm{~K}$ and 4500k. In Figure 19, the experimental data of most colours showed that there are no rules with colour discrimination time and CCT. The colour discrimination time with different CCTs is almost the same when CRI 2012 is 85 .

Table 3 shows the significance analysis with colour discrimination time as the dependent variable, and the independent variable is CRI2012, CCT, and colour of targets. From the table where the $p$ values of colour of targets, CCT, and CRI2012 were all less than 0.05 and close to 0 , the significant correlation between the reaction time and the three factors is strong.

Because changing both CRI2012s and CCTs will affect the reaction time, which means only consider the impact of CCT or CRI2012 is imcomprehensive. The experimental results show that using LEDs of low CCT and high CRI2012 in the tunnel can help to reduce the reaction time of drivers. The results agree with the results in Section 3 too. The results of colour discrimination experiments show that high CRI2012 can improve the speed of colour recognition, which is very beneficial for drivers to observe the indicator and understand the road. Comprehensive experimental results show that the LED with CRI2012 and low CCT is conducive to the driver's rapid and accurate recognition of target and colour of targets. Yellow, white, and silver can be used on the walls, traffic signs, and working clothes of the staff in the tunnel, which are conducive to the driver to find target quickly and clearly.
TABLE 3: Correlation analysis of all experimental data.

\begin{tabular}{lc}
\hline Significance $(p)$ & Colour discrimination time \\
\hline CRI2012 & $p<0.001$ \\
CCT & $p<0.001$ \\
Colour of targets & $p<0.001$ \\
\hline
\end{tabular}

\section{Conclusions}

In this paper, a theoretical analysis and experiment were carried out to investigate the impact of LED colour rendering on reaction time of human eyes in the tunnel interior zone. Firstly, the impact of accidents in the tunnel interior zone is expounded, the types and causes of accidents in the tunnel interior zone and the significance of shortening the reaction time of human eyes were analysed.

Next, several commonly used colour rendering evaluation indexes were also discussed, and CRI2012 was more suitable for evaluating the colour rendering of LEDs in the tunnel. The impact of CRI2012 on contrast is analysed based on the mesopic model MES-2. Low CCT and high CRI2012 can effectively improve the contrast of the target.

Next, a reaction time experiment and a colour discrimination time were designed; one investigates the relationship between CRI2012 and reaction time; another investigates the relationship between CRI2012 and colour discrimination time. Thirty observers attended the experiment.

Then, an experiment was used to measure the reaction time and colour discrimination time of the human eye under different lighting conditions. The results of comprehensive experiments show that the LEDs with low CCT and high CRI2012 have a positive effect on shortening the reaction 
time and colour discrimination time of human eyes. This is conducive to reduce the probability of accidents at the tunnel. The experimental results agree with the results calculation in Section 3. High CRI2012 enables drivers to quickly and accurately identify colours. The experimental results also provide suggestions for the colour of warning signs or facilities at the tunnel.

\section{Data Availability}

The data used to support the findings of the study are available from corresponding author upon request.

\section{Conflicts of Interest}

The authors declare that they have no conflicts of interest.

\section{Acknowledgments}

This paper was supported in part by the National Natural Science Foundation of China, under Grant 61701069. This paper was supported in part by the Fundamental Research Funds for the Central Universities of China, under Grants 3132019340 and 3132019200.

\section{References}

[1] S. Bassan, "Overview of traffic safety aspects and design in road tunnels," IATSS Research, vol. 40, no. 1, pp. 35-46, 2016.

[2] B. Liang, S. He, L. Tähkämö et al., "Lighting for road tunnels: the influence of CCT of light sources on reaction time," Displays, vol. 61, Article ID 101931, 2020.

[3] I. Benekos and D. Diamantidis, "On risk assessment and risk acceptance of dangerous goods transportation through road tunnels in Greece," Safety Science, vol. 91, pp. 1-10, 2017.

[4] H. Wan, Z. Du, and Q. Yan, "The speed control effect of highway tunnel sidewall markings based on color and temporal frequency," Journal of Advanced Transportation, vol. 50, no. 7, pp. 1352-1365, 2016.

[5] Y. Liu, J. Chen, Q. Zhang, and J. Weng, "Influence of light source color temperature on traffic safety at tunnel entrance based on reaction time," Journal of Highway and Transportation Research and Development, vol. 32, p. 114, 2015.

[6] A. Shimojo, H. Takagi, and H. Onuma, "A simulation study of driving performance in long tunnel," in Proceedings of Vehicle Navigation \& Information Systems Conference, Seattle, WA, USA, August 1995.

[7] J. S. Yeung and Y. D. Wong, "The effect of road tunnel environment on car following behaviour," Accident Analysis \& Prevention, vol. 70, pp. 100-109, 2014.

[8] S. Bassan, "Research. Sight distance and horizontal curve aspects in the design of road tunnels vs. highways," Tunnelling and Underground Space Technology, vol. 45, pp. 214-226, 2015.

[9] European Committee for Standardization, Lighting Applications-Tunnel Lighting, CEN CR 14380, Brussels, Belgium, 2003.

[10] China Communications Press, Guidelines for Design of Lighting of Highway Tunnels, Ministry of Transport of People's Republic of China, Beijing, China, 2014.

[11] J. H. Oh, Y. J. Eo, S. J. Yang, and Y. R. Do, "High-color-quality multipackage phosphor-converted LEDs for yellow photolithography room lamp," IEEE Photonics Journal, vol. 7, no. 2, pp. 1-8, 2015.

[12] E. F. Schubert and J. K. Kim, "Solid-state light sources getting smart," Science, vol. 308, no. 5726, pp. 1274-1278, 2005.

[13] H. Y. H. Yi, L. Z. L. Zheyan, W. A. W. Aiguo, L. C. L. Changbin, and F. S. F. Shouzhong, "Research on intelligent control of tunnel lighting system based on LED," in Proceedings of the International Conference on Optoelectronics \& Image Processing, Washington, DC, USA, November 2010.

[14] B. Mao, P. Niu, and C. Huang, "The design of the drive control chip for the solar LED lighting system," Modern Applied Science, vol. 2, p. 75, 2009.

[15] P. Elejoste, I. Angulo, A. Perallos et al., "An easy to deploy street light control system based on wireless communication and LED technology," Sensors, vol. 13, no. 5, pp. 6492-6523, 2013.

[16] F. Leccese, "Remote-control system of high efficiency and intelligent street lighting using a zigbee network of devices and sensors," IEEE Transactions on Power Delivery, vol. 28, pp. 21-28, 2012.

[17] C.-S. Lee, J. Y. Shin, J. Nam, S. Park, S. Y. Chun, and J.-S. Jang, "P1-16: the effect of visual stimuli of LED lighting by color temperature and illuminance control on attention and meditation level of mind," I-Perception, vol. 3, no. 9, p. 630, 2012.

[18] A. Zabiliūtè, R. Vaicekauskas, P. Vitta, and A. Žukauskas, "Phosphor-converted LEDs with low circadian action for outdoor lighting," Optics Letters, vol. 39, no. 3, pp. 563-566, 2014.

[19] H. Jin, S. Jin, L. Chen, S. Cen, and K. Yuan, "Research on the lighting performance of LED street lights with different color temperatures," IEEE Photonics Journal, vol. 7, no. 6, pp. 1-9, 2015.

[20] L. Dong, L. Qin, W. Xu, and L. Zhang, "The impact of LED correlated color temperature on visual performance under mesopic conditions," IEEE Photonics Journal, vol. 9, no. 6, pp. 1-16, 2017.

[21] K. Yamamoto and T. Nagasawa, "Visibility and color-rendering properties of light sources in tunnel lighting," in Proceedings of 26th Session of the CIE, Beijing, China, July 2007.

[22] M. Deng and Y. Dai, "The effect of tunnel light source and tunnel light color to drivers' visual performance," Journal of Chongqing University. Natural Science Edition, vol. 39, pp. 140-145, 2016.

[23] X. Zhang, J. Hu, R. Wang, X. Gao, and L. He, "The comprehensive efficiency analysis of tunnel lighting based on visual performance," Advances in Mechanical Engineering, vol. 9, no. 4, Article ID 168781401769644, 2017.

[24] A. M. Colaco, S. G. Colaco, C. P. Kurian, and S. G. Kini, "Color characterization of multicolor multichip LED luminaire for indoor," Journal of Building Engineering, vol. 18, pp. 19-32, 2018.

[25] J. Laski, C. A. Brunault, R. Schmidt, and S. C. Ryu, "An exploratory study of retail lighting with continuous modulation of color rendering properties to influence shoppers' spatial range of browsing," Journal of Business Research, vol. 111, pp. 148-162, 2020.

[26] F. Szabó, R. Kéri, J. Schanda, P. Csuti, and E. Mihálykó-Orbán, "A study of preferred colour rendering of light sources: home lighting," Lighting Research and Technology, vol. 48, no. 2, pp. 103-125, 2016. 
[27] M. Islam, R. Dangol, M. Hyvärinen, P. Bhusal, M. Puolakka, and L. Halonen, "User acceptance studies for LED office lighting: lamp spectrum, spatial brightness and illuminance," Lighting Research and Technology, vol. 47, no. 1, pp. 54-79, 2015.

[28] S. Jost-Boissard, M. Fontoynont, and J. Blanc-Gonnet, "Perceived lighting quality of LED sources for the presentation of fruit and vegetables," Journal of Modern Optics, vol. 56, no. 13, pp. 1420-1432, 2009.

[29] J. C. Shin, H. Yaguchi, and S. Shioiri, "Change of color appearance in photopic, mesopic and scotopic vision," Optical Review, vol. 11, no. 4, pp. 265-271, 2004.

[30] Central Bureau of the CIE, Method of Measuring and Specifying Colour Rendering Properties of Light Sources, Central Bureau of the CIE, Vienna, Austria.

[31] W. Davis, "Measuring color quality of light sources - art. no. 63370L," in Proceedings of the Sixth International Conference on Solid State Lighting, I. T. Ferguson, N. Narendran, T. Taguchi, and I. E. Ashdown, Eds., p. L3370, San Diego, CA, USA, September 2006.

[32] K. Smet, J. Schanda, L. Whitehead, and R. Luo, "CRI2012: a proposal for updating the CIE colour rendering index," Lighting Research and Technology, vol. 45, no. 6, pp. 689-709, 2013.

[33] N. Pousset, G. Obein, and A. Razet, "Visual experiment on LED lighting quality with color quality scale colored samples," in Proceedings of the CIE 2010 Lighting Quality and Energy Efficiency, Vienna, Austria, August 2010.

[34] K. Lin, N. Liao, D. Zhao, S. Dong, and Y. Li, "Chromatic contrast dependence of reaction time to random-dot stereograms at isoluminance," Color Research \& Application, vol. 41, no. 6, pp. 564-570, 2016.

[35] X. Cai, J. Weng, Y. Hu, and F. J. S. Du, "Research on optimal values of contrast revealing coefficient in road tunnel lighting," Sadhana, vol. 45, 2020.

[36] M. S. Mahadevan, H. E. Bedell, and S. B. Stevenson, "The influence of endogenous attention on contrast perception, contrast discrimination, and saccadic reaction time," Vision Research, vol. 143, pp. 89-102, 2018.

[37] C. An-Seop, K. Intae, K. Hyunsun, and S. Arom, "Evaluation of the visibility of colored objects under LED lighting with various correlated color temperatures," Color Research \& Application, vol. 42, 2017.

[38] M. Rea, J. Bullough, J. Freyssinier-Nova, and A. Bierman, "Technology. A proposed unified system of photometry," Lighting Research and Technology, vol. 36, no. 2, pp. 85-109, 2004.

[39] M. Eloholma and L. Halonen, "New model for mesopic photometry and its application to road lighting," Leukos, vol. 2, no. 4, pp. 263-293, 2006.

[40] Y. He, M. Rea, A. Bierman, and J. Bullough, "Evaluating light source efficacy under mesopic conditions using reaction times," Journal of the Illuminating Engineering Society, vol. 26, no. 1, pp. 125-138, 1997.

[41] D. A. Tipton and E. Medicine, "A review of vision physiology," Aviation Space \& Environmental Medicine, vol. 55, pp. 145-9, 1984.

[42] M. S. Rea and J. D. Bullough, "Making the move to a unified system of photometry," Lighting Research and Technology, vol. 39 , no. 4 , pp. 393-408, 2007. 